\title{
Enol-imino-Keto-enamine Tautomerism in a Diazepine Derivative: How Decisive Are the Intermolecular Interactions in the Equilibrium?
}

\author{
Mariana Rocha, ${ }^{\dagger}$ Diego M. Gil, ${ }^{*}{ }^{\dagger}$ Gustavo A. Echeverría, ${ }^{\ddagger}$ Oscar E. Piro, ${ }^{\ddagger}$ Jorge L. Jios, ${ }^{\S}$ \\ and Sonia E. Ulic ${ }^{*}, \|, \perp_{(1)}$
}

${ }^{\dagger}$ INQUINOA (CONICET - UNT). Instituto de Química Física, Facultad de Bioquímica, Química y Farmacia, Universidad Nacional de Tucumán, San Lorenzo 456, T4000CAN San Miguel de Tucumán, Argentina

${ }^{\ddagger}$ Departamento de Física, Facultad de Ciencias Exactas, Universidad Nacional de La Plata e IFLP (CONICET, CCT-La Plata), C.C. 67, 1900 La Plata, Argentina

${ }^{\S}$ Unidad PLAPIMU-LASEISIC (UNLP-CIC), Departamento de Química, Facultad de Ciencias Exactas, Universidad Nacional de La Plata, 47 esq 115, 1900 La Plata, Argentina

"CEQUINOR (CONICET-UNLP), Facultad de Ciencias Exactas, Universidad Nacional de La Plata, Bv 120 No. 1465,1900 La Plata, Argentina

${ }^{\perp}$ Departamento de Ciencias Básicas, Universidad Nacional de Luján, Rutas 5 y 7, 6700 Luján, Buenos Aires, Argentina

Supporting Information

\begin{abstract}
The strange tautomeric equilibrium behavior exhibited by a new $o$-hydroxyphenyl diazepine derivative when the compound is analyzed both in solution and solid state opens the structural study of the enol-iminoketo-enamine forms and the influence of the intermolecular interactions in their equilibrium. The expected enol-imino form, in which the enol is part of a phenyl system and a strong $\mathrm{O}-\mathrm{H} \cdots \mathrm{N}$ intramolecular hydrogen bond is established, results the most stable tautomer in gas phase (theoretical calculations) and was detected by NMR spectroscopy when the compound was dissolved in aprotic solvents. Nevertheless, the keto-enamine form in which the keto group integrates a cyclohexadienone moiety and the aromaticity of the phenol is lost, was the only tautomer in the crystal lattice according to single-crystal X-ray diffraction, vibrational spectroscopy, and diffuse reflectance results. The last form was also found as the main tautomer in UV-vis and NMR spectroscopy when a protic solvent was employed.
\end{abstract}

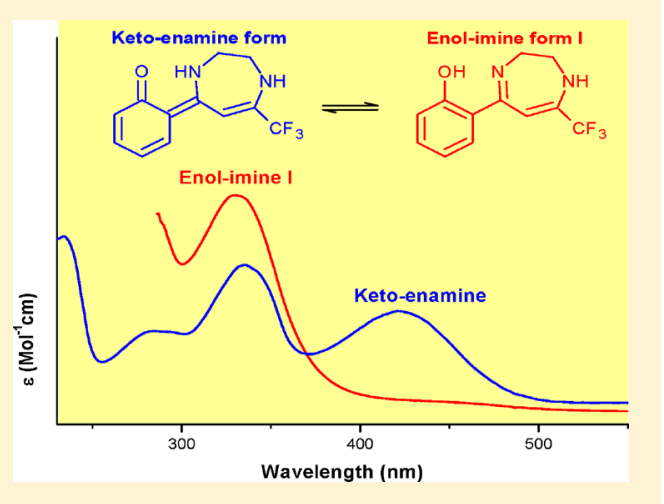

\section{INTRODUCTION}

Diazepines (DZPs) constitute the main pharmacologically active compounds with different applications in medicinal chemistry. 1,4-Diazepine heterocycles such as the well-known zometapine, etizolam, brotizolam, clozapine, dibenzepine, and diazepam $^{1-3}$ cover a wide range of biological activities. Some 1,4-benzodiazepine derivatives were found to be active in the treatment of insomnia, ${ }^{4}$ epilepsy, and alcoholism. ${ }^{5}$ The first benzodiazepine (chlordiazepoxide) was synthesized in 1955 by Sternbach and since 1963 has been marketed as diazepam (Valium). Due to their biological and pharmacological activity, 1,4-diazepines are of continuous interest as antibacterial, ${ }^{6,7}$ antioxidant, ${ }^{8}$ antiviral, ${ }^{9}$ anticonvulsant, ${ }^{10}$ and antitumor ${ }^{11}$ agents, and they have also been used as herbicides ${ }^{12}$ and anti-VIH drugs. ${ }^{13}$

Noncovalent interactions are significant in supramolecular chemistry, crystal engineering, and the biological properties of organic and inorganic compounds. ${ }^{14}$ They are decisive in determining the tautomeric form finally adopted in the crystal lattice, ${ }^{15}$ although this species does not correspond to the geometry of lower energy predicted for the isolated molecule as demonstrated for the enol form of barbituric acid. ${ }^{16}$ It is well-known that the biological activity of DZPs is highly dependent on the conformation of the 1,4-DZP ring, its substituents and the presence of strong hydrogen bond interactions. ${ }^{17}$ In their absence, other noncovalent interactions could be dominant and responsible for the crystal stability and biological properties. Tautomerism also plays an important role in the interactions within the crystal lattice and in the behavior of DZP derivatives as ligands in coordination compounds. For some compounds, the tautomeric equilibria depend on the state of aggregation. In solution studies it has been shown that polar solvents favor the keto-enamine over the less polar form: the enol-imino tautomer. ${ }^{18,19}$

Received: June 17, 2019

Published: August 16, 2019 
Scheme 1. Keto-enamine $(\mathrm{O}=\mathrm{DZP})$ and Enol-imino (OH-DZP) Forms of DZP<smiles>C=CC(F)(F)C1=CC(=C2C=CC=CC2=O)NCCN1</smiles>

Keto-enamine form<smiles>Oc1ccccc1C1=NCCNC(C(F)(F)F)=C1</smiles>

Enol-imino form I<smiles>Oc1ccccc1C1=NCCN=C(C(F)(F)F)C1</smiles>

Enol-imino form II

a)

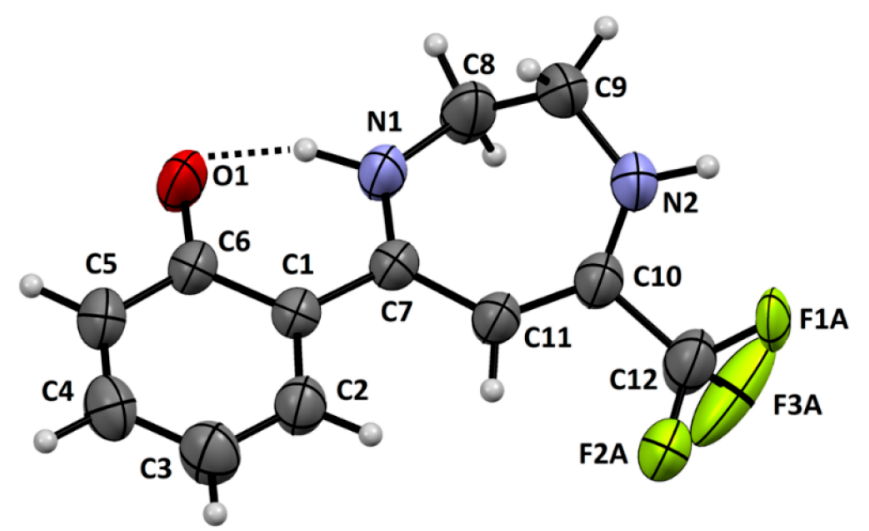

b)

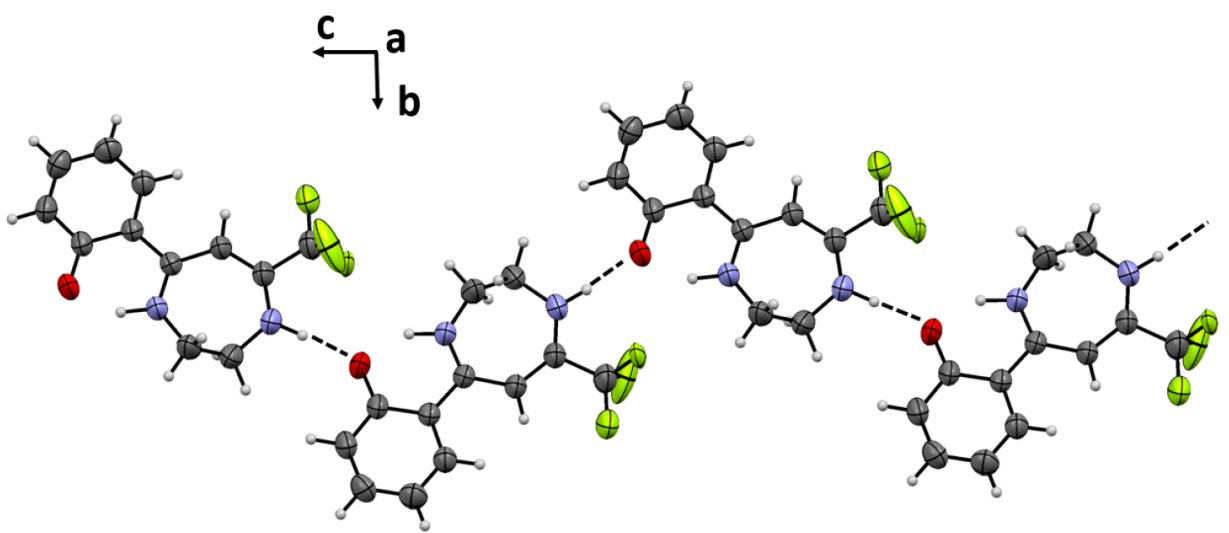

Figure 1. (a) Molecular structure of $\mathbf{O}=\mathbf{D Z P}$ showing the labeling of the non- $\mathrm{H}$ atoms and the displacement ellipsoids at the $30 \%$ probability level except for the fluorine atoms. For clarity, from the three rotationally split positions that model the rotational disorder of the $-\mathrm{CF}_{3}$ group, only the conformation having the largest occupancy with their fluorine atoms drawn as arbitrary disks is shown. Hydrogen bonds are indicated by dashed lines. Crystal symmetry operation: (i) $x-1 / 2,-y+1 / 2,-z+1$; (ii) $x+1 / 2,-y+1 / 2,-z+1$. (b) Projection along the $c$-axis of the $\mathbf{O}=\mathbf{D Z P}$ molecule, indicating the intermolecular $\mathrm{N}-\mathrm{H} \cdots \mathrm{O}$ hydrogen bonds as dashed lines.

In the present study, a new 1,4-diazepine derivative, DZP, containing $o$-hydroxyphenyl and trifluoromethyl substituents, has been synthesized and characterized by different spectroscopies (IR, Raman, UV-vis, and ${ }^{1} \mathrm{H}$ and ${ }^{13} \mathrm{C}$ NMR). Structural single-crystal $\mathrm{X}$-ray diffraction together with density functional theory (DFT) calculations and vibrational, UV-vis, and NMR analysis allowed us to study the supramolecular crystal packing and the molecular structure, both in solution and in the solid. Furthermore, natural bond orbital (NBO) and QTAIM analyses were performed to obtain quantitative information on the nature of several intermolecular contacts in the solid. Hirshfeld surface analysis along with 2D fingerprint plots were used to explore the crystal packing modes to visualize the intermolecular interactions, including the relative percentage of each type of them. The DZP tautomeric equilibrium between enol-imino, $\mathbf{O H}-\mathrm{DZP}$, and keto-enamine, $\mathbf{O}=\mathbf{D Z P}$, forms (see Scheme 1) has been investigated by UV-vis and NMR spectroscopy in different solvents. The preference for the $\mathbf{O H}$ DZP or the $\mathbf{O}=\mathrm{DZP}$ form depends on the aggregation state and was interpreted in terms of the nature and strength of the intra- and intermolecular interactions.

\section{RESULTS AND DISCUSSION}

2.1. Crystallographic Structural Results. Figure 1a shows an ORTEP view of the molecular structure of DZP as the keto-enamine tautomer $(\mathbf{O}=\mathbf{D Z P})$. In Table 1 , a selection of bond lengths and angles were compared with the corresponding computed values for each tautomeric form: $\mathbf{O}=\mathrm{DZP}$ and OH-DZP. The compound crystallizes in the orthorhombic group $\mathrm{Pbcn}$ with eight molecules in the 
Table 1. Experimental $(\mathrm{O}=\mathrm{DZP})$ and Calculated $(\mathrm{O}=\mathrm{DZP}$ and OH-DZP) Bond Lengths ( $\AA$ ), Angles (deg), and Dihedral Angles (deg) for DZP

\begin{tabular}{|c|c|c|c|}
\hline \multirow[b]{2}{*}{ parameters } & \multirow[b]{2}{*}{ experimental } & \multicolumn{2}{|c|}{$\begin{array}{c}\text { calcd }[\text { B3LYP/6-311+ } \\
+ \text { G(d,p)] }\end{array}$} \\
\hline & & OH-DZP & $\mathrm{O}=\mathrm{DZP}$ \\
\hline \multicolumn{4}{|l|}{ bond lengths ( } \\
\hline $\mathrm{N} 1-\mathrm{H}$ & $0.99(3)$ & & 1.062 \\
\hline $\mathrm{O} 1-\mathrm{H}$ & & 1.005 & \\
\hline $\mathrm{C} 6-\mathrm{O} 1$ & $1.304(2)$ & 1.339 & 1.273 \\
\hline $\mathrm{C} 6-\mathrm{C} 5$ & $1.407(3)$ & 1.403 & 1.437 \\
\hline $\mathrm{C} 5-\mathrm{C} 4$ & $1.359(3)$ & 1.384 & 1.368 \\
\hline $\mathrm{C} 4-\mathrm{C} 3$ & $1.383(3)$ & 1.399 & 1.418 \\
\hline $\mathrm{C} 3-\mathrm{C} 2$ & $1.365(3)$ & 1.385 & 1.371 \\
\hline $\mathrm{C} 2-\mathrm{C} 1$ & $1.404(2)$ & 1.409 & 1.424 \\
\hline $\mathrm{C} 6-\mathrm{C} 1$ & $1.431(2)$ & 1.425 & 1.465 \\
\hline $\mathrm{C} 1-\mathrm{C} 7$ & $1.459(2)$ & 1.484 & 1.438 \\
\hline C7-N1 & $1.315(2)$ & 1.302 & 1.335 \\
\hline $\mathrm{N} 1-\mathrm{C} 8$ & $1.450(3)$ & 1.446 & 1.445 \\
\hline $\mathrm{C} 8-\mathrm{C} 9$ & $1.507(4)$ & 1.542 & 1.535 \\
\hline $\mathrm{C} 9-\mathrm{N} 2$ & $1.446(3)$ & 1.454 & 1.453 \\
\hline $\mathrm{N} 2-\mathrm{C} 10$ & $1.321(3)$ & 1.358 & 1.359 \\
\hline $\mathrm{C} 10-\mathrm{C} 11$ & $1.364(3)$ & 1.359 & 1.361 \\
\hline $\mathrm{C} 11-\mathrm{C} 7$ & $1.433(2)$ & 1.464 & 1.453 \\
\hline \multicolumn{4}{|l|}{ angles (deg) } \\
\hline $\mathrm{O} 1-\mathrm{C} 6-\mathrm{C} 5$ & $120.5(2)$ & 117.6 & 120.3 \\
\hline $\mathrm{C} 6-\mathrm{C} 5-\mathrm{C} 4$ & $121.9(2)$ & 120.7 & 121.8 \\
\hline $\mathrm{C} 5-\mathrm{C} 4-\mathrm{C} 3$ & $120.7(2)$ & 120.3 & 121.0 \\
\hline $\mathrm{C} 4-\mathrm{C} 3-\mathrm{C} 2$ & $119.3(2)$ & 119.3 & 119.5 \\
\hline $\mathrm{C} 3-\mathrm{C} 2-\mathrm{C} 1$ & $122.4(2)$ & 122.2 & 122.1 \\
\hline $\mathrm{C} 2-\mathrm{C} 1-\mathrm{C} 6$ & $118.0(2)$ & 117.5 & 118.7 \\
\hline $\mathrm{C} 6-\mathrm{C} 1-\mathrm{C} 7$ & $120.7(1)$ & 120.6 & 119.4 \\
\hline $\mathrm{C} 1-\mathrm{C} 7-\mathrm{N} 1$ & $116.4(2)$ & 117.1 & 117.3 \\
\hline $\mathrm{C} 7-\mathrm{N} 1-\mathrm{C} 8$ & $125.4(2)$ & 121.3 & 126.4 \\
\hline $\mathrm{N} 1-\mathrm{C} 8-\mathrm{C} 9$ & $112.8(2)$ & 113.7 & 113.1 \\
\hline $\mathrm{C} 8-\mathrm{C} 9-\mathrm{N} 2$ & $112.4(2)$ & 111.5 & 115.5 \\
\hline $\mathrm{C} 9-\mathrm{N} 2-\mathrm{C} 10$ & $122.2(2)$ & 124.4 & 124.7 \\
\hline $\mathrm{N} 2-\mathrm{C} 10-\mathrm{C} 11$ & $130.4(2)$ & 129.7 & 130.5 \\
\hline $\mathrm{C} 10-\mathrm{C} 11-\mathrm{C} 7$ & $130.7(2)$ & 128.9 & 130.2 \\
\hline $\mathrm{C} 11-\mathrm{C} 10-\mathrm{C} 12$ & $117.1(2)$ & 118.1 & 117.6 \\
\hline $\mathrm{N} 2-\mathrm{C} 10-\mathrm{C} 12$ & $112.5(2)$ & 112.2 & 111.8 \\
\hline \multicolumn{4}{|l|}{ dihedral angles (deg) } \\
\hline $\mathrm{O} 1-\mathrm{C} 6-\mathrm{C} 1-\mathrm{C} 7$ & $-1.2(3)$ & -2.435 & -2.929 \\
\hline $\mathrm{C} 6-\mathrm{C} 1-\mathrm{C} 7-\mathrm{N} 1$ & $6.9(2)$ & 9.491 & 3.505 \\
\hline $\mathrm{N} 1-\mathrm{C} 8-\mathrm{C} 9-\mathrm{N} 2$ & $81.3(3)$ & 81.15 & 78.35 \\
\hline $\mathrm{C} 7-\mathrm{C} 11-\mathrm{C} 10-\mathrm{N} 2$ & $5.2(4)$ & 0.105 & -0.566 \\
\hline
\end{tabular}

asymmetric unit. The bonding structure of $\mathbf{O}=\mathbf{D Z P}$ is based in a ciclohexadienone fragment, a less common and less stable moiety compared to the phenol counterpart (with stabilization by aromaticity). The observed bond distances and angles are in agreement with corresponding data reported for a related compound, 5-(2-hydroxyphenyl)-7-trifluoromethyl-1,4,8triazabicyclo(5.3.0)dec-4-ene, ${ }^{20}$ although in this case the enol-imino tautomer was postulated. As shown in Scheme 1, enol-imino and keto-enamine are two of the most important tautomeric forms of DZP. The existence of one or both structural forms were analyzed in some $o$-hydroxy Schiff bases. $^{21-23}$ The preference of one form over the other depends mainly on the molecular structure and in the solid state and solution on the competition of intra- versus intermolecular interactions. Even so, both tautomeric forms can coexist simultaneously in the crystal lattice, ${ }^{24}$ which could be identified by two crystallographic characteristics: (a) the position of the acidic hydrogen atom and (b) the nature of the $\mathrm{C}-\mathrm{O}, \mathrm{C}-\mathrm{N}$, and $\mathrm{C}-\mathrm{C}$ bonds involved in the six-atoms intramolecular pseudo ring. DZP exists as a keto-enamine tautomer in the solid state, with a $\mathrm{N1}-\mathrm{H}$ bond length of 0.99(3) A. This is in accordance with the C6-O1 bond length $[1.304(2) \AA]$ value, slightly longer than the typical $\mathrm{C}=\mathrm{O}$ double bond, possibly due to the strong $\mathrm{N}-\mathrm{H} \cdots \mathrm{O}$ intramolecular interaction. The $\mathrm{C} 1-\mathrm{C} 7$ bond length $[1.459(2) \AA]$ is shorter than the typical $\mathrm{C}-\mathrm{C}$ single bond, and the bond length $\mathrm{C} 7-\mathrm{N} 1=1.315(2) \AA$ is an indicative of the single bond character of this bond.

Moreover, calculated characteristic bond lengths and angles for both tautomeric forms of DZP are listed in Table 1 and compared with the keto-enamine form obtained experimentally in the solid state. When the $\mathbf{O}=\mathbf{D Z P}$ form is considered, the chain involved would be $\mathrm{O} 1=\mathrm{C} 6-\mathrm{C} 1=\mathrm{C} 7-\mathrm{N} 1-\mathrm{H}$, instead of the $\mathrm{O} 1(\mathrm{H})-\mathrm{C} 6=\mathrm{C} 1-\mathrm{C} 7=\mathrm{N} 1-\mathrm{H}$ fragment for the $\mathrm{OH}$ DZP form. Thus, it is expected a shorter O1-C6 bond distance in $\mathbf{O}=\mathbf{D Z P}$ (carbonyl) than in OH-DZP (enol). On the contrary, the $\mathrm{C} 7-\mathrm{N} 1$ bond should be longer in $\mathrm{O}=\mathbf{D Z P}$ (amino) than in OH-DZP (imino). Table 1 shows that the experimental bond distances are just in the middle of those in the calculated tautomeric forms. For the C6-O1 enol/keto bond, the obtained distances in the OH-DZP and $\mathbf{O}=\mathbf{D Z P}$ calculated forms, the average of both, and in the $\mathbf{O}=\mathbf{D Z P}$ experimental form are 1.339, 1.273, 1.306, and 1.304(2) A, respectively. In the imino/amine $\mathrm{C} 7-\mathrm{N} 1$ bond, the corresponding values are $1.302,1.335,1.318$, and $1.315(2) \AA$, respectively. These results indicate that the keto-enamine form by itself is not the best picture to describe the structure of the compound in the crystal lattice. To obtain a most adequate structure, the concept of the resonance assisted hydrogen bonding (RAHB) $)^{25}$ should be considered. The RAHB applied to $\mathbf{O}=\mathbf{D Z P}$ is showed in Scheme 2, which includes the

Scheme 2. RAHB Model Applied to the $\mathrm{O}=\mathrm{DZP}$ Structure in the Solid State

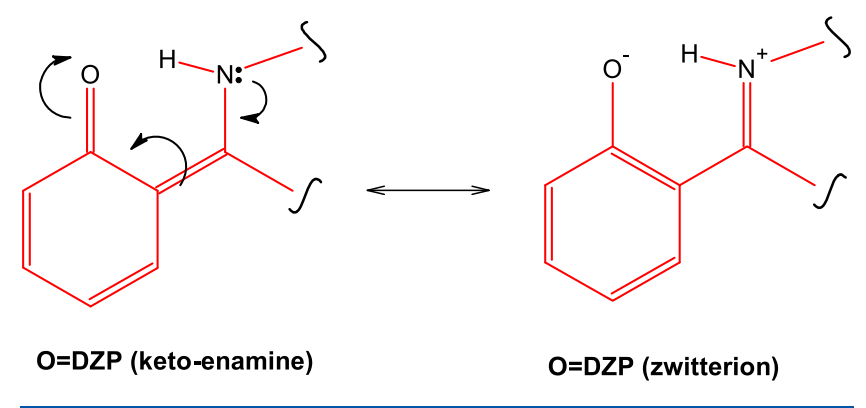

zwitterionic enol-imino form. Thus, the $\mathbf{O}=\mathbf{D Z P}$ structure in the solid state is better described as a resonance hybrid with two major and almost equally important contributing forms. Theoretical calculations on similar hydrogen bonding tautomeric keto-enamine-enol-imino heterocyclic systems demonstrated that the intramolecular hydrogen bonds are resonanceassisted. $^{26}$

Although the cyclohexadienone ring in the $\mathbf{O}=\mathrm{DZP}$ seems to be less favored by the loss of aromaticity present in the phenol of the OH-DZP, the RAHB model allows the $\pi$ bonding delocalization that explains the nearly planar cyclohexadienone- $\mathrm{C} 1=\mathrm{C} 7$ fragment. This planarity is further 
stabilized by a strong intramolecular $\mathrm{NH} \cdots \mathrm{O}$ bond involving the amino $\mathrm{N} 1-\mathrm{H}$ donor and the acceptor carbonyl oxygen atom $[\mathrm{d}(\mathrm{N} 1 \cdots \mathrm{O})=2.492(2) \AA, \mathrm{d}(\mathrm{H} \cdots \mathrm{O})=1.59(3) \AA$, $\left.\angle(\mathrm{N} 1-\mathrm{H} \cdots \mathrm{O})=148(2)^{\circ}\right]$, which form $S(6)$ ring motifs as shown in Figure 1a. The zwitterionic form (Scheme 2) contributes to reinforcing this hydrogen bonding. In addition, nonclassical $\mathrm{C} 11-\mathrm{H} 11 \cdots \mathrm{F} 2 \mathrm{~A}$ intramolecular hydrogen bonds are present in the crystal (see Table 2). It is remarkable that

Table 2. Intra- and Intermolecular Hydrogen Bond Parameters for $\mathrm{O}=\mathrm{DZP}$

\begin{tabular}{lcccc}
\multicolumn{1}{c}{$\mathrm{D}-\mathrm{H} \cdots \mathrm{A}^{a}$} & $d(\mathrm{D}-\mathrm{H})$ & $d(\mathrm{H} \cdots \mathrm{A})$ & $d(\mathrm{D} \cdots \mathrm{A})$ & $\angle(\mathrm{D}-\mathrm{H} \cdots \mathrm{A})$ \\
intramolecular & & & & \\
$\mathrm{N} 1-\mathrm{H} 1 \cdots \mathrm{O} 1$ & 0.99 & 1.59 & $2.4923(1)$ & 148 \\
$\mathrm{C} 11-\mathrm{H} 11 \cdots \mathrm{F} 2 \mathrm{~A}$ & 0.92 & 2.29 & $2.7137(2)$ & 107 \\
intermolecular & & & & \\
$\mathrm{N} 2-\mathrm{H} 2 \cdots \mathrm{O}^{\mathrm{i}}$ & 0.94 & 1.77 & $2.7087(2)$ & 175 \\
$\mathrm{~N} 1-\mathrm{H} 1 \cdots \mathrm{F} 3 \mathrm{C}^{\mathrm{ii}}$ & 0.99 & 2.47 & $3.183(2)$ & 128
\end{tabular}

${ }^{a}$ Symmetry codes: (i) $-1 / 2+x, 1 / 2-y, 2-z$; (ii) $1 / 2-x, 1 / 2-y$, $1 / 2+z$.

the nonplanarity of the molecule is due to the folding of the seven-membered ring, which adopts a half-chair conformation, where the bond angles around the methylene groups N2-C9$\mathrm{C} 8$ and $\mathrm{N} 1-\mathrm{C} 8-\mathrm{C} 9$ are $112.4(2)$ and $112.8(2)^{\circ}$, respectively.

2.2. Analysis of Intermolecular Interactions. The crystal lattice is further stabilized by intermolecular $\mathrm{N}-\mathrm{H} \cdots \mathrm{O}$ hydrogen bonds, involving the second amine $(\mathrm{N} 2-\mathrm{H})$ group and the carbonyl oxygen atom of a neighboring molecule $\left[\mathrm{d}\left(\mathrm{N} 2 \cdots \mathrm{O}^{\prime}\right)=2.709(2) \AA, \mathrm{d}\left(\mathrm{H} \cdots \mathrm{O}^{\prime}\right)=1.77(3) \AA, \angle(\mathrm{N} 2-\mathrm{H} \cdots\right.$ $\left.\left.\mathrm{O}^{\prime}\right)=175(2)^{\circ}\right]$. This gives rise to a chain structure that extends along the crystal $c$-axis (see Figure $1 b$ ). The supramolecular assembly of $\mathbf{O}=\mathbf{D Z P}$ is also governed by $\mathrm{N} 1-\mathrm{H} 1 \cdots \mathrm{F} 3 \mathrm{C}$ hydrogen bonds with $\mathrm{d}(\mathrm{H} 1 \cdots \mathrm{F} 3 \mathrm{C})=2.47 \AA$ and $\angle(\mathrm{N} 1-\mathrm{H} 1 \cdots \mathrm{F} 3 \mathrm{C})=128^{\circ}$ (see Table 2). Additionally, intramolecular offset-face-to-face $\pi$ stacking contacts (see Figure S1) are observed between the cyclohexadienone rings (Cg1 … Cg1 distances of $4.4781(3) \AA$ ) and represent a moderately weak $\pi \cdots \pi$ contact. As observed in Figure S2, the 3D supramolecular network is completed with $\mathrm{C}-\mathrm{H} \cdots \pi$ contacts. The $\mathrm{C} 3-\mathrm{H} 3 \cdots \mathrm{Cg} 1$ interactions $(\mathrm{H} 3 \cdots \mathrm{Cg} 1$ distance $=3.372 \AA$ ) involve the cyclohexadienone ring ( $\mathrm{Cg} 1$ centroid) and the $\mathrm{H} 3$ atom of the phenyl ring of a neighbor molecule.

The Hirshfeld surfaces of $\mathbf{O}=\mathbf{D Z P}$ showed in Figure 2, mapped with $d_{\text {norm }}$, shape index, and curvedness properties, illustrate the nature and extent of various intermolecular interactions. The short and dominant intermolecular contacts are shown as bright red areas on the Hirshfeld surface, indicating the existence of hydrogen-bonding interactions. The red regions labeled 1 in the $d_{\text {norm }}$ map are attributed to N2$\mathrm{H} 2 \cdots \mathrm{O} 1$ contacts (see Figure $1 \mathrm{~b}$ ). The contacts associated with the $\mathrm{O}$ atom represent the strongest intermolecular hydrogen bond interactions in the crystal of DZP, as reflected by the geometrical parameters showed in Table 2 . The F $\cdots H$ contacts can be observed as bright red areas along with light red spots (labeled 2) representing $\mathrm{N}-\mathrm{H} \cdots \mathrm{F}$ hydrogen bonds associated with $\mathrm{N} 1-\mathrm{H} 1 \cdots \mathrm{F} 3 \mathrm{C}$ interactions in the crystal. Interestingly, visible bright red spot labeled as 3 , in the $d_{\text {norm }}$ map, corresponds to $\mathrm{H} \cdots \mathrm{F}$ intermolecular contacts associated with nonclassical $\mathrm{C}-\mathrm{H} \cdots \mathrm{F}$ hydrogen bonds (see Figure S3), with $2.630 \AA$ A. In addition, C…C contacts are clearly visible as a
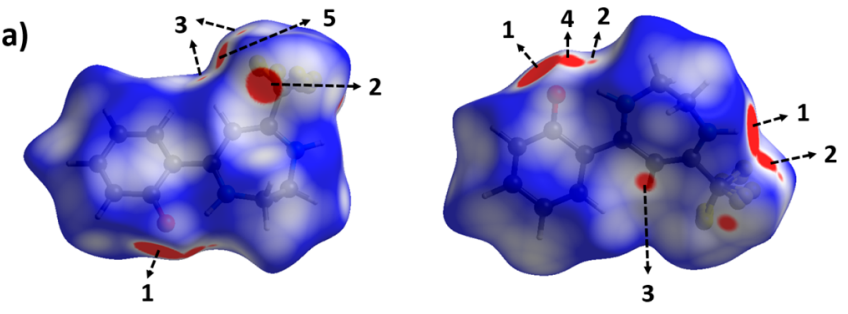

b)

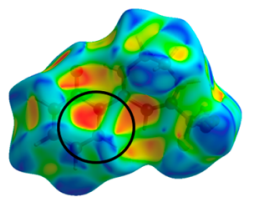

c)

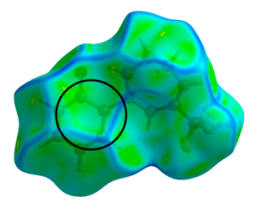

Figure 2. Hirshfeld surfaces of $\mathbf{O}=\mathbf{D Z P}$ mapped with (a) $d_{\text {norm }}$ function in two orientations; molecule in column 2 rotated by $180^{\circ}$ around the horizontal axis of the plot. (b) Shape index. (c) Curvedness. For descriptions of labels (a) and circles (b and c) see the text.

pair of white spots. The red spots labeled 4 and 5 are attributed to $\mathrm{O} 1 \cdots \mathrm{F} 3 \mathrm{~A}$ and $\mathrm{F} \cdots \mathrm{F}$ contacts, respectively.

Furthermore, the Hirshfeld surfaces were mapped with shape index and curvedness properties to confirm the existence of $\pi$-stacking interactions. In the shape index diagram (Figure $2 \mathrm{~b})$, the pattern of convex blue and concave red triangles indicates the existence of $\pi$-stacking interactions in the structure of $\mathbf{O}=\mathbf{D Z P} .^{27,28}$ Figure $2 \mathrm{~b}$ clearly shows that the red and blue triangles are observed over the cyclohexadienone rings due to the presence of slipped parallel $\pi$-stacking interactions. The existence of $\pi \cdots \pi$ interactions is also evident as relatively large and green flat regions delineated by the black circle on the curvedness surface (see Figure 2c).

The fingerprint plots are generally disaggregated to highlight particularly the close contact of atom pairs, allowing to separate contributions from different interaction types, which usually appear overlapped in the full fingerprint. The full and disaggregated 2D fingerprint (FP) plots of the main intermolecular interactions are depicted in Figure 3, including the relative contribution of the individual intermolecular contacts to the Hirshfeld surface area of $\mathbf{O}=\mathbf{D Z P}$. The size and shape of the fingerprints illustrate the significant differences between the intermolecular interaction patterns. The $\mathrm{H} \cdots \mathrm{H}$ interactions are in the middle of scattered points in the disaggregated 2D FP maps, with minimum values of $\left(d_{\mathrm{e}}+\right.$ $d_{\mathrm{i}}$ ) around $2.4 \AA$. As observed in Figure 3, the $\mathrm{H} \cdots \mathrm{H}$ intermolecular contacts are predominant in the structure of $\mathrm{O}=\mathrm{DZP}$ with a contribution of $30.6 \%$ to the total Hirshfeld surface area. The closest $\mathrm{F} \cdots \mathrm{H} / \mathrm{H} \cdots \mathrm{F}$ contacts are represented on the FP plots by characteristic sharp spikes at $d_{\mathrm{e}}+d_{\mathrm{i}} \approx 2.5 \AA$, contributing $29.7 \%$ to the Hirshfeld surface area, while noteworthy F...F contacts were also found (5.1\%). Significant $\mathrm{C} \cdots \mathrm{H}$ contacts are present in the $\mathbf{O}=\mathrm{DZP}$ structure, and the intermolecular $\mathrm{O} \cdots \mathrm{H} / \mathrm{H} \cdots \mathrm{O}$ contacts are represented by sharp spikes with minimum $d_{\mathrm{e}}+d_{\mathrm{i}}$ values of $\sim 1.75 \AA$. The $\mathrm{C} \cdots \mathrm{H} /$ $\mathrm{H} \cdots \mathrm{C}$ FP plot also shows $\mathrm{C}-\mathrm{H} \cdots \pi$ interactions, which appear as a pair of characteristic wings around $d_{\mathrm{e}}+d_{\mathrm{i}} \approx 3.1 \AA$. The C $\cdots \mathrm{C}$ contacts are concentrated just about $d_{\mathrm{e}}=d_{\mathrm{i}} \approx 1.8 \AA$ as green dots in the full FP (see Figure 3), which indicates the presence of $\pi \cdots \pi$ interactions in the structure.

The atoms in molecules (AIM) approach is a very useful tool for evaluating the intra- and intermolecular hydrogenbonding interactions. The existence of a bond critical point 

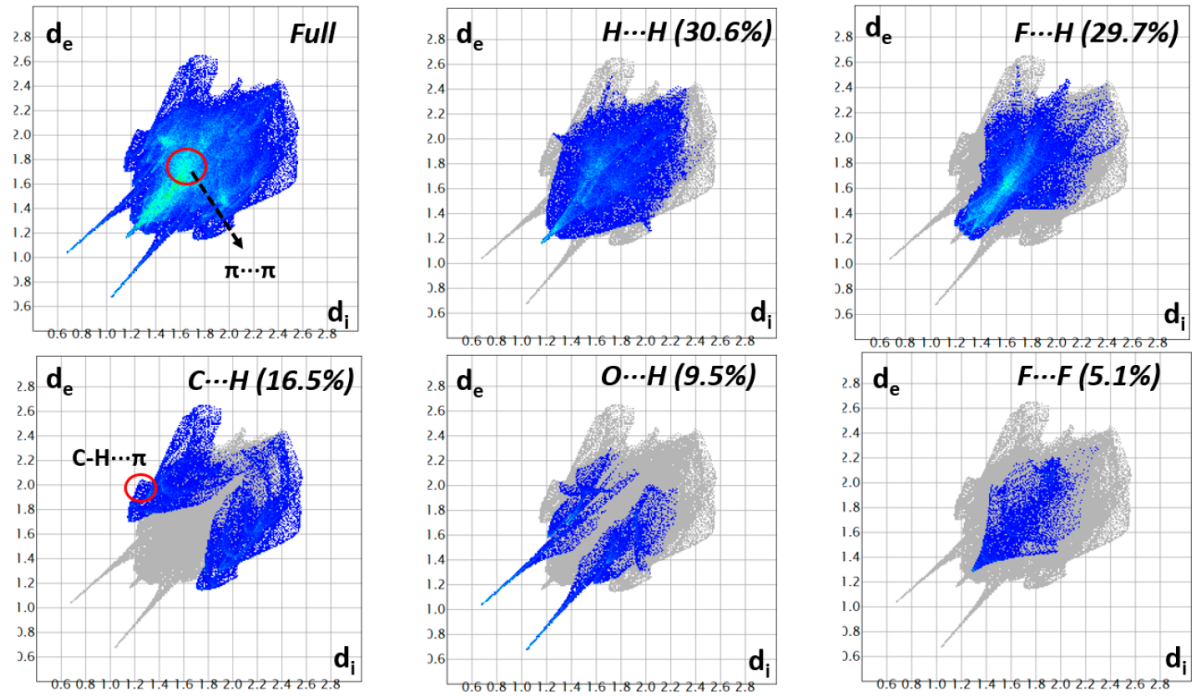

Figure 3. Full and disaggregated $2 \mathrm{D}$ fingerprint plots of the intermolecular contacts for $\mathbf{O}=\mathbf{D Z P}$.

Table 3. Topological Parameters Obtained by AIM Approach for the Molecular Associations of $\mathrm{O}=\mathrm{DZP}{ }^{a}$

\begin{tabular}{lccccccc}
\multicolumn{1}{c}{ interaction } & $\mathrm{d}(\mathrm{H} \cdots \mathrm{A})$ & $\rho(r)$ & $\nabla^{2}(\rho)$ & $G$ & $H$ & & \\
intermolecular & & & & & & & \\
$\mathrm{N} 2-\mathrm{H} \cdots \mathrm{O} 1$ & 1.774 & 0.0367 & 0.1432 & 0.0351 & -0.00075 & -0.0358 & -11.23 \\
$\mathrm{C} 8-\mathrm{H} \cdots \mathrm{F}$ & 2.821 & 0.0034 & 0.0150 & 0.0029 & -0.00077 & -0.0037 & -1.179 \\
$\mathrm{H} 9 \mathrm{~A} \cdots \mathrm{H} 5$ & 2.448 & 0.0038 & 0.0112 & 0.0024 & -0.00044 & -0.0028 & -0.882 \\
intramolecular & & & & & & -0.0460 & -14.44 \\
$\mathrm{~N} 1-\mathrm{H} \cdots \mathrm{O} 1$ & 1.594 & 0.0642 & 0.1841 & 0.0584 & 0.01237 &
\end{tabular}

${ }^{a} \rho$ : electron density at the BCP $(\mathrm{au}) . \nabla^{2}(\rho)$ : Laplacian of electron density (au). G: electron kinetic energy density (au). H: the electron energy density $(\mathrm{au}) . V$ : the electron potential energy density $(\mathrm{au}) . E_{\mathrm{HB}}$ : hydrogen bond energy $(\mathrm{kcal} / \mathrm{mol})$. BCP: bond critical point.

(BCP) and bond path connecting two atoms provides unambiguous evidence of hydrogen bonds. Starting from a dimer formed from the crystal structure coordinates of $\mathbf{O}=$ DZP, a series of topological parameters and hydrogen bond energies $\left(E_{\mathrm{HB}}\right)$ at the BCPs were calculated in Table 3. The molecular graph shows a six-membered ring intramolecular hydrogen bond leading ring critical points (RCP) (yellow points in Figure S4). The strong $\mathrm{N} 1-\mathrm{H} \cdots \mathrm{O} 1$ interaction is confirmed by the high value of electron density $(0.0642 \mathrm{au})$ and interaction energy of $-14.44 \mathrm{kcal} / \mathrm{mol}$. The molecular geometry is the result of various inter- and intramolecular interactions that contribute to the packing of the molecules in the crystal lattice. Anyway, more precise analysis performed with the AIM approach shows a more complex set of molecular interactions (Table 3). The values of electron density, the Laplacian of the electron density at the BCP (criteria range: $0.002-0.035$ au and $0.024-0.139$ au for $\rho(r)$ and $\nabla^{2} \rho(r)$, respectively) as well as the shape of the bond paths linking the proton and the acceptor atom confirm the existence of every hydrogen bond ${ }^{29}$ (see Figure S4). The value of electron density at the BCP can be used as a measure of strength of the interactions more accurately than the geometrical parameters. $^{30,31}$ Based on the electron density values at the $\mathrm{BCP}$, the strongest intermolecular hydrogen bond corresponds to N2$\mathrm{H} \cdots \mathrm{O} 1$ with an interaction energy of $-11.23 \mathrm{kcal} / \mathrm{mol},{ }^{32}$ supporting such dimeric assembly. Additionally, C8-H...F interactions were observed in the AIM plot. The electron density value of 0.0034 au as well as the $\mathrm{H} \cdot \cdots \mathrm{F}$ distance of 2.821 Å confirms a typical, moderately weak hydrogen bond with an interaction energy of $-1.179 \mathrm{kcal} / \mathrm{mol}$. Interestingly, although the $\mathrm{H} \cdots \mathrm{H}$ interactions (involving $\mathrm{H} 9 \mathrm{~A}$ and $\mathrm{H} 5$ ) are the weakest $\left(E_{\mathrm{HB}}\right.$ of $\left.-0.882 \mathrm{kcal} / \mathrm{mol}\right)$, they contribute to stabilize the dimer structure (Table 3 and Figure S4).

2.3. Quantum-Chemical Calculations. The OH-DZP and $\mathrm{O}=\mathrm{DZP}$ tautomeric structures were optimized and their computed geometrical parameters were compared with the experimental ones (Table 1). Besides, a potential energy curve analysis was performed to evaluate the effects of the intramolecular proton transfer on the energy and on the molecular geometry. Starting from the optimized most stable OH-DZP tautomer in vacuum, the curve of the relative energy against the $\mathrm{O} 1-\mathrm{H} 1$ bond length was plotted (Figure 4). This bond was selected as the redundant internal coordinate and varied from 0.9 to $1.7 \AA$, in 0.05 steps. The $\mathbf{O}=\mathrm{DZP}$ tautomer appears as a local minimum at $3.0 \mathrm{kcal} \mathrm{mol}^{-1}$ higher in energy respect to the $\mathbf{O H}-\mathrm{DZP}$ form. In addition, the energy barrier of $3.25 \mathrm{kcal} \mathrm{mol}^{-1}$ between both tautomeric forms suggests that they can be easily interchanged in a dynamic equilibrium. The computed difference between both tautomers in the electronic energy $\left(\Delta E^{\circ}\right)$ and free energy $\left(\Delta G^{\circ}\right)$ at $\mathrm{B} 3 \mathrm{LYP} / 6-311+$ $+\mathrm{G}(\mathrm{d}, \mathrm{p})$ approximation were 2.82 and $2.52 \mathrm{kcal} \mathrm{mol}^{-1}$, with OH-DZP being the most stable tautomer.

NBO analysis provides a useful method for studying intraand intermolecular interactions among bonds and conjugative interactions in several molecular systems. For this analysis, the interaction between donor and acceptor NBO orbitals can be estimated quantitatively by the second-order perturbation theory. ${ }^{33}$ Large values of energy between donors and acceptors $E^{(2)}$ indicates that the tendency to donate electrons by the donors increases and the extension of the conjugation of the 


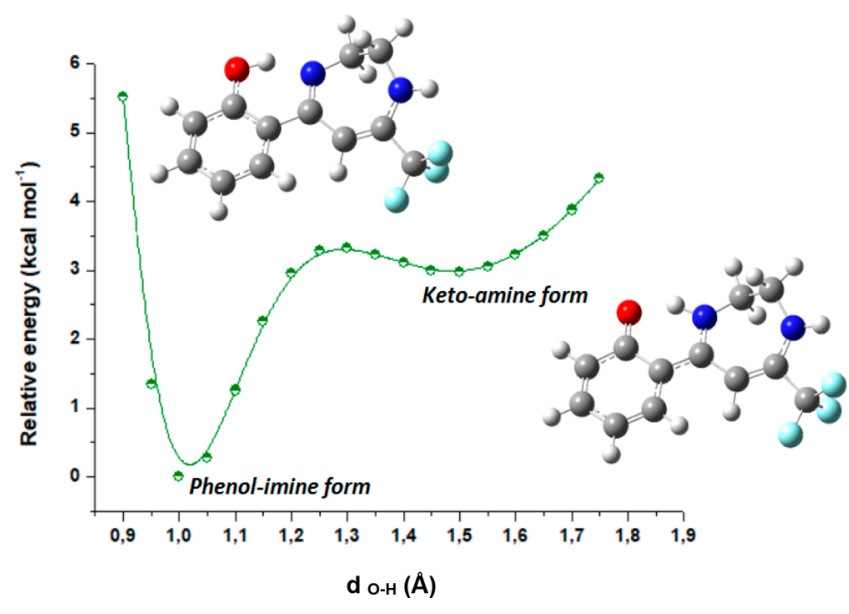

Figure 4. Curve of relative energy against the $\mathrm{O} 1-\mathrm{H} 1$ bond length in vacuum, calculated at the $\mathrm{B} 3 \mathrm{LYP} / 6-311++\mathrm{G}(\mathrm{d}, \mathrm{p})$ level of theory, indicating the two possible tautomeric structures of DZP.

whole system is greater. In the NBO hydrogen bond analysis, the $E^{(2)}$ value between the lone pair of atom Y and $\sigma^{*}$ of the $\mathrm{X}-\mathrm{H}$ bond is a measure of the intensity of the $\mathrm{X}-\mathrm{H} \cdots \mathrm{Y}$ interaction. The results of the second-order perturbation theory of the Fock matrix (Table S2) indicates that the intramolecular hydrogen bonding in the keto-enamine (LP O1 $\left.\rightarrow \sigma^{*} \mathrm{~N} 1-\mathrm{H}\right)$ is $10 \mathrm{kcal} / \mathrm{mol}$ stronger than that for the enolimino tautomer $\left(\mathrm{LP} \mathrm{N} 1 \rightarrow \sigma^{*} \mathrm{O} 1-\mathrm{H}\right)$. These results are in accordance with the shorter $\mathrm{O} 1 \cdots \mathrm{H}(1.594 \AA)$ and higher stabilization energy of the keto-enamine structure. As mentioned above, in the crystal packing of $\mathbf{O}=\mathbf{D Z P}$ molecules are stabilized by other hydrogen bonds between the carbonyl $(\mathrm{C}=\mathrm{O})$ of one molecule and amine $(\mathrm{N}-\mathrm{H})$ group of another. The NBO analysis for the dimeric structure of $\mathbf{O}=\mathbf{D Z P}$ (taken also from the crystal structure coordinates) allows to evaluate the intermolecular $\mathrm{O} 1 \cdots \mathrm{N} 2-\mathrm{H} 2$ interaction. The $E^{(2)}$ for the LP O1 $\rightarrow \sigma^{*} \mathrm{~N} 2-\mathrm{H} 2$ gives an additional stabilization of $14.99 \mathrm{kcal} / \mathrm{mol}$ to this tautomeric form. The donoracceptor intramolecular interactions also reveal that the interactions LP N2 $\rightarrow \pi^{*} \mathrm{C} 10-\mathrm{C} 11$ further stabilize the system providing an energy value of 53.29 and $51.60 \mathrm{kcal} / \mathrm{mol}$ for the $\mathbf{O H}-\mathbf{D Z P}$ and $\mathbf{O}=\mathbf{D Z P}$ tautomers, respectively. In addition, the hyperconjugative interaction LP O1 $\rightarrow \sigma^{*} \mathrm{C} 1-$ C6 has the higher stabilization energy for the $\mathbf{O}=\mathbf{D Z P}$ tautomer with a $E^{(2)}$ interaction value of $13.99 \mathrm{kcal} / \mathrm{mol}$.

Molecular electrostatic potential (MEP) is related to the electron density and is a very useful descriptor to get a better understanding toward the attractive character of weak intermolecular hydrogen bonds for packing stabilization. The MEP maps were computed highlighting the blue and red areas for positive and negative regions, respectively. The MEP plot for the $\mathbf{O}=\mathrm{DZP}$ tautomeric form, obtained from XRD data is shown in Figure S7. It shows a deep red region of highly negative electrostatic potential $(-0.099 \mathrm{au})$ surrounding the $\mathrm{O} 1$ atom of the carbonyl group and a complementary deep blue region with the highest positive electrostatic potential value of +0.1151 au in the vicinity of $\mathrm{N} 2-\mathrm{H}$ group of the diazepine ring. These results contributed to explain the formation and strength of intermolecular $\mathrm{N} 2-\mathrm{H} \cdots \mathrm{O} 1$ hydrogen bonds in this structure. The red region of high electrostatic potential $(-0.087 \mathrm{au})$ around of the center of the phenyl ring is attributed to weak $\mathrm{C} 3-\mathrm{H} 3 \cdots \pi$ interactions, as discussed in section 2.2. In accordance with these results, the MEP maps allowed a visual and quantitative study on the strength and electrostatic nature of weak intermolecular interactions in the crystal stabilization of the title compound.

One of the most interesting observations of the previous analysis focuses on the differences observed in the distribution of the charge for each $\mathbf{O}=\mathbf{D Z P}$ and $\mathbf{O H}-\mathbf{D Z P}$ tautomers. The calculated electric dipole moment of the keto-enamine $(5.3 \mathrm{D})$ is greater than that of the enol-imino form $(3.6 \mathrm{D})$. In the last form, the highest positive and negative electrostatic potential are in the amine $(\mathrm{N} 2-\mathrm{H})$ and imino $(=\mathrm{N} 1)$ groups in the heterocyclic ring, whereas for the keto-enamine form, the deep red region moves toward the carbonyl oxygen atom. This result explains an increase in the intermolecular dipole-dipole interaction and a greater stabilization of the keto-enamine form in the solid state and in polar aprotic solvents as is discussed below.

2.4. Vibrational Results. The experimental IR absorption and Raman dispersion spectra of $\mathbf{O}=\mathbf{D Z P}$ (Figure S8) were assigned on the basis of the calculated frequencies. The weak and broad absorption observed at $2768 \mathrm{~cm}^{-1}$ in the IR spectrum (Table S3) is assigned to the $\mathrm{N} 1-\mathrm{H}$ stretching mode. This observed low frequency is in accordance with the strong intramolecular $\mathrm{N} 1-\mathrm{H} \cdots \mathrm{O} 1$ hydrogen bond (X-ray diffraction data, section 2.1). ${ }^{24,34}$ The Raman band located at $1573 \mathrm{~cm}^{-1}$ is assigned to the $\mathrm{N} 1-\mathrm{H}$ in-plane bending mode, whereas the IR absorption at $987 \mathrm{~cm}^{-1}\left(985 \mathrm{~cm}^{-1}\right.$ in Raman) corresponds to the $\mathrm{N} 1-\mathrm{H}$ out-of-plane bending mode. The $\nu(\mathrm{C}=\mathrm{O})$ stretching region is interesting to detect the intraand intermolecular hydrogen bonding, shifting this band to lower frequencies. Consequently, the $\mathrm{C}=\mathrm{O}$ (coupled with the $\mathrm{C} 10=\mathrm{C} 11)$ stretching mode was assigned to the strong band at $1635 \mathrm{~cm}^{-1}$ in the IR spectrum. ${ }^{35}$ The broad absorption located at $3242 \mathrm{~cm}^{-1}$ is attributed to the $\mathrm{N} 2-\mathrm{H}$ stretching of the diazepine group, which is blue-shifted compared to the $\mathrm{N}-$ $\mathrm{H}$ stretching modes in 1,4-diazepine derivatives, ${ }^{36}$ indicating that the intermolecular $\mathrm{N} 2-\mathrm{H} \cdots \mathrm{O} 1$ hydrogen bonds affect the force constant of the $\mathrm{N}-\mathrm{H}$ group. The medium intensity IR band located at $1540 \mathrm{~cm}^{-1}$ is attributed to the $\mathrm{C}-\mathrm{N}$ stretching vibration of the diazepine ring.

2.5. Electronic Spectra. The UV-vis absorption spectroscopy was also employed to identify the tautomeric species of DZP in solution. The electronic spectra were recorded in the solid state and in different solvents (ethanol, DMSO and toluene) in the 200-800 $\mathrm{nm}$ spectral region. The spectra of both tautomers were calculated with the TD-DFT (B3LYP/6$311++\mathrm{G}(\mathrm{d}, \mathrm{p}))$ approach using the polarizable continuum model (PCM) solvent modeling method.

It was found for some $o$-hydroxy Schiff bases that the ketoenamine tautomeric form prevails in polar solvents, while enolimino has been observed mostly in nonpolar solvents. ${ }^{37}$ In addition, these compounds could interact through hydrogen bonds with protic solvents, stabilizing the keto-enamine structure. It turns out that the solvent is an important factor that affects the tautomeric equilibria.

The DZP UV-vis spectrum of the solid (using the diffuse reflectance accessory) was obtained to identify the ketoenamine tautomer absorptions, according to the X-ray diffraction results. Figure 5 shows the calculated electronic (vacuum and ethanol) and experimental spectra of the solid and the ethanolic and DMSO solutions. In view of the crystal structure results, the intermolecular hydrogen bonding N2$\mathrm{H} \cdots(\mathrm{O}) \mathrm{C}$, which is established when the DZP adopts the ketoenamine form, seems to particularly stabilize this structure in 


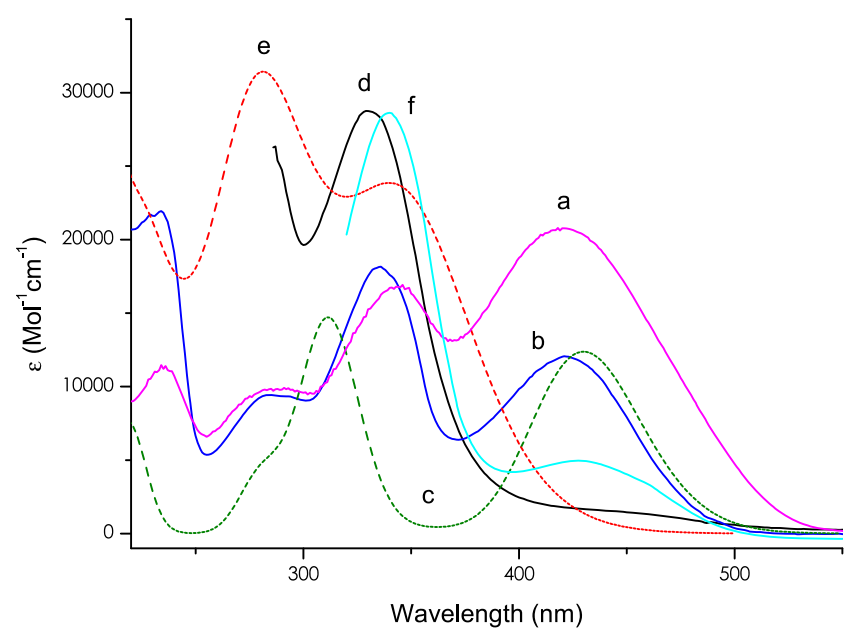

Figure 5. Electronic spectra of DZP: (a) solid; (b) ethanol solution; (c) calculated (B3LYP/6-31 G*, ethanol); (d) toluene solution; (e) calculated (B3LYP/6-31 G*, toluene); (f) DMSO solution.

the solid phase. When DZP is dissolved in a protic solvent such as ethanol, the $\mathrm{O}-\mathrm{H}$ ethanolic group probably competes with the $\mathrm{N} 2-\mathrm{H}$ and interacts with the carbonyl oxygen of DZP, stabilizing the keto-enamine form which predominates in the solid. Nevertheless, the UV DZP spectrum in a polar aprotic solvent, such as DMSO, presents the same behavior as in ethanol, revealing that dipole-dipole interactions (see section 2.3) probably play also an important role in the stabilization of the keto-enamine tautomer when no interactions between DZP and solvent through hydrogen bonding are possible. Both of them could be the reason why the ketoenamine tautomer is the one that prevails both in solution (polar protic and aprotic solvents) and in the solid phase. However, according to Figure 5, which also depicts DZP calculated (vacuum and toluene) and experimental electronic spectra using toluene as solvent, the enol-imino tautomer predominates in the nonprotic solvents. This could be attributed to the fact that intermolecular hydrogen-bonding interactions are not favored between the DZP molecules, and consequently, the aromaticity of the phenolic DZP ring is recovered. The wavelength of the observed bands, the corresponding calculated values and a tentative assignment of the electronic transitions are listed in Table 4.

2.5.1. Keto-enamine Tautomer. The electronic spectrum of the keto-enamine tautomer in ethanol solution $\left(1 \times 10^{-4} \mathrm{M}\right)$ is presented in Figure 5. According to the results summarized in
Table 4, the band at $232 \mathrm{~nm}$ (calcd 212 and $222 \mathrm{~nm}$ ) is attributed to HOMO- $2 \rightarrow \mathrm{LUMO}+1$ and HOMO $\rightarrow$ LUMO +2 transitions, corresponding principally to $\pi \rightarrow \pi^{*}$ excitations within the rings. The absorptions at 286 and $335 \mathrm{~nm}$ are originated by HOMO- $3 \rightarrow$ LUMO and HOMO- $\rightarrow$ LUMO transitions, respectively. They come basically from contributions of nonbonding oxygen and nitrogen atoms and $\pi$ orbitals of the whole molecule to $\pi^{*}$ of the carbonyl group and both rings. The band centered at $423 \mathrm{~nm}$ is dominated by excitations from HOMO to LUMO orbitals, which is originated by excitations from $\pi$ orbitals of both rings and nonbonding orbitals of oxygen and nitrogen atoms to $\pi^{*}$ orbitals of the hexadiene ring and $\mathrm{C}=\mathrm{O}$ and $\mathrm{C}=\mathrm{N}$ groups.

2.5.2. Enol-imino Tautomer. The absorption spectrum of the enol-imino tautomer in toluene solution $\left(1 \times 10^{-4} \mathrm{M}\right)$ is displayed from $285 \mathrm{~nm}$ (Figure 5) due to the solvent cut-of below $300 \mathrm{~nm}$. The band located at $287 \mathrm{~nm}$ arises from HOMO-2 $\rightarrow$ LUMO and HOMO-3 $\rightarrow$ LUMO transitions from $\pi$ orbitals of the aromatic ring, $\mathrm{C}=\mathrm{N}$ bond and nonbonding orbitals of oxygen and nitrogen (N1) atoms to $\pi^{*} \mathrm{C}=\mathrm{N} 1$ and $\mathrm{C}-\mathrm{N} 2$ bonds.

The observed absorption at around $330 \mathrm{~nm}$ (Figure 5) clearly corresponds to HOMO $\rightarrow$ LUMO excitations from $\pi$ orbitals of the benzene ring and nitrogen and oxygen nonbonding orbitals to the $\pi^{*}$ of $\mathrm{C}-\mathrm{N} 1$ and $\mathrm{C}-\mathrm{N} 2$ bonds.

As observed in Figure 5, the DZP UV-vis spectra of solid (a), dissolved and calculated in ethanol (b and c) and using a polar aprotic solvent (DMSO, $\left.2.9 \times 10^{-4} \mathrm{M}\right)$, are in very good agreement, confirming that the keto-enamine is the prevailing tautomer in the solid phase. In addition, theoretical calculations (e) predict fairly well the experimental spectrum of DZP in toluene (d), at least above $300 \mathrm{~nm}$, which supports the presence of the enol-imino form in nonpolar solvents.

2.6. NMR Spectroscopy. The tautomeric equilibria (depicted in Scheme 1) were studied by NMR spectroscopy at $25{ }^{\circ} \mathrm{C}$ dissolving DZP in $\mathrm{CDCl}_{3}$ and $\mathrm{CD}_{3} \mathrm{OD}$, nonpolar aprotic, and polar protic solvents, respectively. The ${ }^{1} \mathrm{H},{ }^{13} \mathrm{C}$, and ${ }^{19} \mathrm{~F}$ NMR chemical shifts in $\mathrm{CDCl}_{3}$ and $\mathrm{CD}_{3} \mathrm{OD}$ for DZP are shown in Table S4.

The UV-vis results (see section 2.5) indicate that the tautomeric preference depends on the nature of the solvent, moreover, the $\mathbf{O}=\mathbf{D Z P}$ could also be the main tautomer both when using a polar protic and a nonprotic solvent. Although theoretical calculations predicted a more stable enol-imino tautomer over the keto-enamine form, the last one is the unique tautomer in the crystal lattice. Why is the tautomer with less stability finally imposed as the only structure in solid

Table 4. Experimental and Calculated Electronic Absorption Bands (in $\mathbf{n m}$ ) and Tentative Assignment for Keto-enamine and Enol-imino Tautomeric Forms of DZP

\begin{tabular}{|c|c|c|c|c|c|c|c|c|c|c|}
\hline DZP $(\mathbf{D R})^{a}$ keto-enamine & \multicolumn{5}{|c|}{ DZP (EtOH) keto-enamine } & \multicolumn{5}{|c|}{ DZP (toluene) enol-imino } \\
\hline expt & $\operatorname{expt}^{b}$ & calcd $(\mathrm{EtOH})$ & $f$ & assignment & $\%$ & expt & calcd (toluene) & $f$ & assignment & $\%$ \\
\hline 234 & 232 & 214 & 0.088 & $\mathrm{H}-2 \rightarrow \mathrm{L}+1$ & 85 & & 226 & 0.144 & $\mathrm{H}-1 \rightarrow \mathrm{L}+1$ & 100 \\
\hline & & 222 & 0.098 & $\mathrm{H} \rightarrow \mathrm{L}+2$ & 68 & & & & & \\
\hline 287 & 286 & 282 & 0.085 & $\mathrm{H}-3 \rightarrow \mathrm{L}$ & 94 & 287 & 274 & 0.146 & $\mathrm{H}-2 \rightarrow \mathrm{L}$ & 92 \\
\hline & & & & & & & 286 & 0.100 & $\mathrm{H}-3 \rightarrow \mathrm{L}$ & 83 \\
\hline 344 & 335 & 311 & 0.296 & $\mathrm{H}-2 \rightarrow \mathrm{L}$ & 90 & 330 & 350 & 0.177 & $\mathrm{H} \rightarrow \mathrm{L}$ & 100 \\
\hline & $(340)$ & & & & & & & & & \\
\hline 421 & 423 & 429 & 0.252 & $\mathrm{H} \rightarrow \mathrm{L}$ & 100 & & & & & \\
\hline & $(427)$ & & & & & & & & & \\
\hline
\end{tabular}

${ }^{a}$ Diffuse reflectance. ${ }^{b}$ Wavelengths in DMSO solution are shown in parentheses. 
Scheme 3. Possible Isomeric Equilibria for $\mathrm{DZP}$ in $\mathrm{CD}_{3} \mathrm{OD}$ Solution
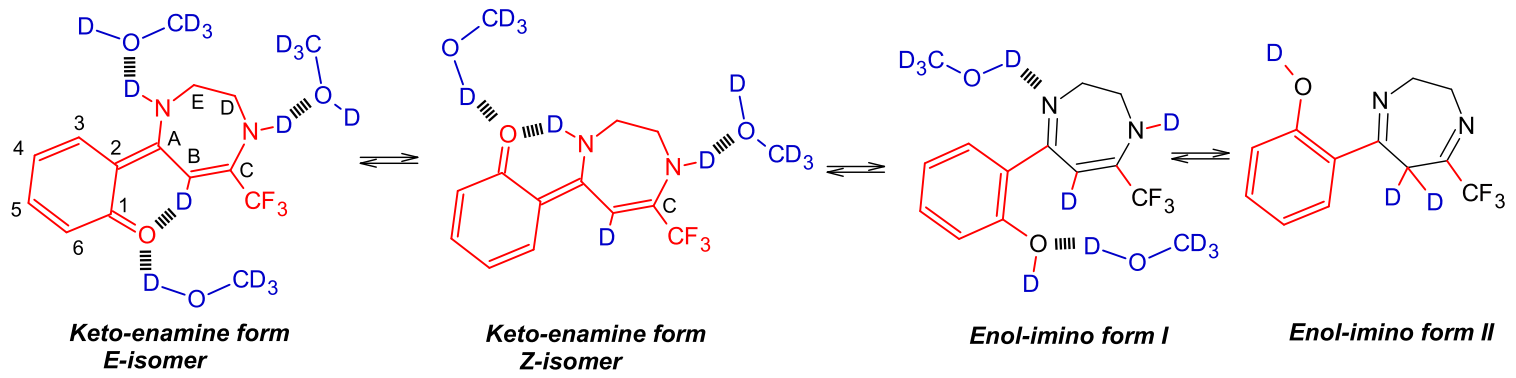

Enol-imino form I

Enol-imino form II

state? The adopted form of a molecule must be interpreted in terms of not only its intra- but also its intermolecular interactions with the matrix. The last kind of attractive contacts are responsible for stabilizing the observed tautomer in DZP. In a similar way, the results obtained in the UV-vis spectrum of DZP dissolved in ethanol could be understood if it is assumed that the hydrogen bond solvent-substrate interaction displaces its intramolecular hydrogen bond. The intramolecular hydrogen bonding observed, in the enol-imino form I (Scheme 1), is one of the most important attractive interactions that explain the lower energy calculated for this tautomer compared with the keto-enamine form. When the DZP molecules are surrounded by those of a protic solvent, like ethanol, the intermolecular solvent-substrate hydrogen interaction takes place, breaking the intramolecular hydrogen one. The loss of this hydrogen bridge allows the diazepine heterocycle to move away from the phenyl ring plane leaving also the $\mathrm{N}-\mathrm{H}$ groups free to establish hydrogen bonds with the surrounding solvent molecules. Furthermore, since the $\mathbf{O}=\mathrm{DZP}$ dipole moment is higher than that calculated for HO-DZP (see section 2.3), the solvent-solute interactions of the $\mathbf{O}=\mathbf{D Z P}$ are favored in polar protic and nonprotic solvents, possibly by means of hydrogen bonding and dipoledipole interactions.

To prove this presumption and to confirm the UV-vis results, the tautomeric equilibria of DZP were investigated in both aprotic nonpolar and protic polar solvents, using the NMR spectroscopy as analytical tool. ${ }^{38}$ For clarity, the NMR assignment was made according to the numbering depicted in Scheme 3.

2.6.1. NMR Spectroscopy in $C D C_{3}$. The protonic spectrum of DZP shows one set of signals (only one tautomer in solution). The broad singlet at an unusual low field of 16.41 $\mathrm{ppm}$ is indicative of a very strong intramolecular hydrogen bonding between the acidic $\mathrm{O}-\mathrm{H}$ donor and the imino $(: \mathrm{NR}=)$ acceptor groups. It is consistent with one of the two enol-imino tautomers (form I or II) but not with the ketoenamine tautomer since this form involves a weaker hydrogen bond interaction (see Scheme 1). The observation of a singlet at $5.99 \mathrm{ppm}$ (which integrates by $1 \mathrm{H}$ ), assigned to the vinyl proton together with the absence of methylene signals in the region between 3 and $4 \mathrm{ppm}$, allows us to conclude that the diazepine enol-imino form I is the only stable tautomer present in deuterated chloroform solution. A broad singlet at $5.43 \mathrm{ppm}$ for the $\mathrm{N}-\mathrm{H}$ proton completes the assignment for this tautomer. The ${ }^{13} \mathrm{C}$ NMR spectrum reveals the $\mathrm{C}=\mathrm{N}$ imino carbon atom as the most deprotected signal at $169.0 \mathrm{ppm}$, whereas the aromatic carbon bonded to the $\mathrm{OH}$ group appears at $164.8 \mathrm{ppm}$. The ${ }^{19} \mathrm{~F}$ NMR spectrum complements this study showing only one signal at $-68.88 \mathrm{ppm}$ for the unique tautomer.

2.6.2. NMR Spectroscopy in $C D_{3} O D$. The ${ }^{1} \mathrm{H},{ }^{13} \mathrm{C}$, and ${ }^{19} \mathrm{~F}$ $\mathrm{NMR}$ were measured in $\mathrm{CD}_{3} \mathrm{OD}$ with the aim of observing the keto-enamine form. Scheme 3 shows the possible main species in equilibria in deuterated methanol, two corresponding to the $E / Z$ isomer of the keto-enamine tautomer and two for the enol-imino form. Analogous to that observed in the electronic spectra, the keto-enamine (higher dipole moment) form interacts more strongly and effectively with the solvent (in blue) than the enol-imino (higher dipole moment) forms. However, it should be noted that the UV-vis and NMR spectra results are not strictly comparable since in the NMR hydrogen atoms are replaced by deuterium $\left({ }^{2} \mathrm{H}\right)$, making the hydrogen-bond interaction larger and weaker than the observed in the ethanolic solution UV-vis spectrum.

In this deuterated solvent, all acidic protons of DZP are expected to be lost in the ${ }^{1} \mathrm{H}$ NMR spectra, since they are interchanged by deuterium. However, the structural differences between the keto-enamine and the enol-imino forms should be large enough to be detected by the protons and carbon atoms neighboring the keto-enamine and enol-imino functions.

Observing the proton spectrum of DZP in $\mathrm{CD}_{3} \mathrm{OD}$ at $25^{\circ} \mathrm{C}$, two set of signals appear due to the coexistence of two species in equilibrium. The relationship of 93:7 between them is calculated after peak integration, showing that in this protic solvent the equilibrium is strongly shifted to the keto-enamine form according to the NMR elucidation. This result agrees with the structure found in the crystal lattice (X-ray diffraction) and in ethanolic solution (UV-vis spectroscopy). As described above, in $\mathrm{CD}_{3} \mathrm{OD}$ the intramolecular hydrogen bond is lost and the diazepine heterocycle can even move to the phenyl ring plane, increasing the solvent-substrate hydrogen $\mathrm{N}-\mathrm{H}$ bond interactions (see Scheme 3 ).

Although the enol-imino form II was not detected, the ${ }^{1} \mathrm{H}$ and ${ }^{13} \mathrm{C}$ NMR spectra show that the proton at the vinyl $\mathrm{C}-\mathrm{B}$ position is substituted by deuterium in both the keto-enamine and the enol-imino form I. Moreover, the ${ }^{13} \mathrm{C}$ NMR spectrum shows at this position a triplet as result of the one-bond coupling with deuterium. These evidence prove the existence of the enol-imino form II, from which the deuterium atoms are interchanged with the enol-imino form I and keto-enamine tautomers. A few years ago, NMR investigations dealing with the deuteration mechanism in aromatic protons were conclusive and demonstrated that the H/D interchange (using $\mathrm{CD}_{3} \mathrm{OD}$ as solvent) in a series of ketimines is promoted by the keto-enamine tautomerization and proceeds across a methylene intermediate like the enol-imino form II. ${ }^{39}$

It is interesting to note that $\mathrm{H}-\mathrm{B}$ protons are only observed when the spectrum was measured after sample dissolution in 
Scheme 4. Solvent-Substrate Deuterium Exchange in the Diazepine System

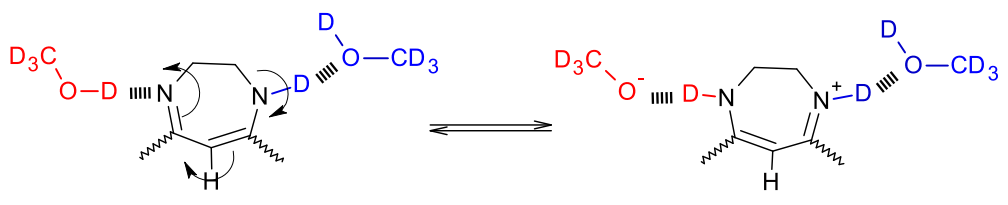

$C D_{3} \mathrm{O}-\mathrm{D}-\ddot{\mathrm{N}}=\mathrm{C}(\mathrm{R})-\mathrm{C}(\mathrm{D})=\mathrm{C}\left(\mathrm{R}^{\mathrm{F}}\right)-\ddot{\mathrm{N}}(\mathrm{D})-\mathrm{D}-\mathrm{OCD}_{3}$

$\mathrm{CD}_{3} \mathrm{O}^{-}-(\mathrm{D}) \ddot{\mathrm{N}}-\mathrm{C}(\mathrm{R})=\mathrm{C}(\mathrm{D})=\mathrm{C}\left(\mathrm{R}^{\mathrm{F}}\right)=\stackrel{+}{\mathrm{N}}(\mathrm{D})-\mathrm{D}-\mathrm{OCD}_{3}$

$\mathrm{CD}_{3} \mathrm{OD}$. The singlet at $5.89 \mathrm{ppm}$ integrates for 0.7 proton and was assigned to $\mathrm{H}-\mathrm{B}$ (vinylic proton) of the main ketoenamine form. A second singlet at $6.82 \mathrm{ppm}$ integrates for 0.07 protons and was assigned to the vinylic proton of the enolimino form I. Both singlets disappeared when the spectrum was measured after $48 \mathrm{hs}$. The high deprotection observed for this singlet in the enol-imino form I (shifted to low field $c a 1$ ppm respect to the keto-enamine form) could be understood observing the Scheme 4. The electronic delocalization improvement in the diazepine system reinforces the magnetic anisotropy deprotection on the vinylic proton that resonates at $6.82 \mathrm{ppm}$ before its deuterium exchange.

This behavior is observed also in the aromatic phenyl protons. When the ${ }^{1} \mathrm{H}$ NMR spectrum in $\mathrm{CD}_{3} \mathrm{OD}$ is examined, the less abundant enol-imino form I shows signals of similar multiplicities and coupling constant values but shifted to low fields compared with the main keto-enamine tautomer. This is expected due to a higher ring-current effect of the benzenoid phenol moiety of the enol-imino in comparison with the cyclohexadienone ring presents in both keto-enamine isomers. Looking at the possible forms depicted in Scheme 3, it could be postulated that the 93:7 relationship found is due to the balance between the $E / Z$ isomers instead of the ketoenamine-enol-imino tautomers. This new hypothesis allows the $E$ isomer to be designated as the minor species because the vinyl hydrogen should be more deshielded by the intramolecular hydrogen bond interaction (first structure) but cannot explain the differences found in the rest of the aromatic hydrogens and carbon atoms (see discussion below).

The ${ }^{13} \mathrm{C}$ NMR spectrum is of crucial importance to study the structures participating in the tautomeric equilibrium in deuterated methanol solution, especially the chemical shifts of the carbon atoms at the C-1 and C-A positions (see numbering in Scheme 3). Considering that the equilibrium is strongly shifted to the main tautomer in a relationship 93:7 according to the ${ }^{1} \mathrm{H} \mathrm{NMR}$, it is expected to clearly observe the signals of the main tautomer, while those belonging to the minor tautomer could be unobservable because of its low intensity (below noise) or covered by other signals. These weak signals can be observed above 150 ppm, a relatively clean spectral area, where only the resonance of high deshielded carbon atoms is expected. The Table S4 shows two signals at 171.6 $(\mathrm{C}=\mathrm{O})$ and $169.8(=\mathrm{C}-\mathrm{N})$ ppm for $\mathrm{C}-1$ and C-A (ketoenamine form), while for the same carbon atoms it was possible to observe small signals at $157.4(\mathrm{C}-\mathrm{OH})$ and 178.8 $(\mathrm{C}=\mathrm{N}) \mathrm{ppm}$ corresponding to the enol-imino form I. To prove this assignment, a long-range (HMBC) correlation spectroscopy was performed. Cross peaks were found connecting $\mathrm{H}-3$ with the signals at 171.6 and $169.8 \mathrm{ppm}$ but $\mathrm{H}-5$ is connected only with the peak at $171.6 \mathrm{ppm}$. These results allow the above proposed assignment for the main tautomer. In a similar way, the small signal at $157.4 \mathrm{ppm}$ has two cross peaks with $\mathrm{H}-3$ (8.15 ppm) and $\mathrm{H}-5$ (7.86 ppm) of the minor enol-imino tautomer and so, this signal was assigned to the ipso carbon at the phenol group (C-1). Moreover, only one cross peak with $\mathrm{H}-3$ was found for the signal at $178.8 \mathrm{ppm}$, corresponding to the $\mathrm{C}-\mathrm{A}$ imino carbon atom. The observed results are consistent with the changes in the involved functions. A great protection of $14.2 \mathrm{ppm}$ is detected for C-1 when this carbonyl carbon (major tautomer) converts itself into a phenol carbon (minor tautomer). Instead, the C-A carbon atom experiments a reasonable deshielding of $9 \mathrm{ppm}$ going from amino to imino function.

\section{CONCLUSIONS}

The molecules of DZP in solid state are in the form of the keto-enamine ( $\mathbf{O}=\mathbf{D Z P})$ tautomer [(5Z)-5-(6-oxocyclohexa2,4-dien-1-ylidene)-7-trifluoromethyl-2,3,4,5-tetrahydro- $1 \mathrm{H}$ 1,4-diazepine], whereas the enol-imino (HO-DZP) form is preferred in nonprotic solvents and in the gas phase [5-(2hydroxyphenyl)-7-trifluoromethyl-2,3-dihydro-1H-1,4-diazepine]. In the last form, the intramolecular enol-imino hydrogen bond interaction together with the preservation of the aromatic phenol system is crucial for the greater stability of this tautomer. Despite the lower intramolecular $\mathrm{N}-\mathrm{H} \cdots \mathrm{O}$ hydrogen bond interaction strength compared with the enol-imino one and the loss of the phenol ring aromaticity, the $\mathbf{O}=\mathbf{D Z P}$ structural form is detected by single-crystal XRD analysis. It exhibits a planar conformation due to intramolecular $\mathrm{N} 1-\mathrm{H} \cdots$ $\mathrm{O} 1$ hydrogen bonding interaction between the $\mathrm{N}-\mathrm{H}$ amino group and the carbonyl oxygen atom. An intermolecular N2$\mathrm{H}$.. O 1 hydrogen bond between the second nitrogen atom and the carbonyl group support the keto-enamine tautomer in the crystal. In addition, the supramolecular assembly is stabilized by $\mathrm{C}-\mathrm{H} \cdots \pi, \mathrm{C}-\mathrm{H} \cdots \mathrm{F}$, and $\pi$-stacking interactions. The strength and stability of these intra- and intermolecular interactions were studied by means of the AIM and NBO analyses, which agree with the experimental results. UVvisible and NMR experiments revealed that in tautomeric $\mathbf{O}=$ DZP-HO-DZP equilibrium in solution, the predominance of one form is strongly dependent on the employed solvent. The keto-enamine form is preferred in protic solvents in which the intermolecular solute-solvent interactions are stablished. The enol-imino tautomer was observed mainly in the aprotic solvents since, in the absence of stabilizing solute-solvent interactions, the more stable OH-DZP tautomer (as a free molecule) predominates. The greater calculated electric dipole moment of the keto-enamine (5.3 D) over the enol-imino form (3.6 D) contributes to increase the intermolecular dipoledipole interaction of the $\mathbf{O}=\mathbf{D Z P}$ in solid state and in polar solvents.

\section{EXPERIMENTAL SECTION}

4.1. Materials and Physical Measurements. All starting materials were purchased from standard commercial sources and used without further purification. Solvents were reagent grade and 
were used as received. The ${ }^{1} \mathrm{H}(600.1 \mathrm{MHz})$ and ${ }^{13} \mathrm{C}(150.9 \mathrm{MHz})$ NMR spectra were recorded on a Bruker Advance III spectrometer in $\mathrm{CDCl}_{3}$ using TMS as internal standard. The IR absorption spectra of the solid were measured on a FTIR PerkinElmer GX1 in the 4000$400 \mathrm{~cm}^{-1}$ frequency range with spectral resolution of $4 \mathrm{~cm}^{-1}$. The Raman spectrum of the solid was performed in the $3500-100 \mathrm{~cm}^{-1}$ range at room temperature on a Thermoscientific DXR Raman microscope using a diode pump and solid-state laser of $780 \mathrm{~nm}$, with spectral resolution of $5 \mathrm{~cm}^{-1}$. The electronic spectra of DZP in ethanol, dimethylformamide, chloroform, and toluene were recorded on a Beckman/DU 7500 spectrophotometer in the spectral region of $200-800 \mathrm{~nm}$, using a quartz cell of $10 \mathrm{~mm}$ optical path length. Diffuse reflectance UV-vis (DR) spectra were performed with a Shimadzu UV-2600 spectrophotometer using $\mathrm{BaSO}_{4}$ as reference.

4.2. Synthesis of DZP. The compound was synthesized by mixing $10 \mathrm{~mL}$ of an ethanolic solution of 2-(trifluoromethyl)chromone (4 mmol, $0.856 \mathrm{~g})$ and ethylendiamine $(4 \mathrm{mmol}, 0.240 \mathrm{~g})$ with continuous stirring at room temperature. After a few minutes, an orange solid became visible, and the mixture was stirred for about 30 min. The precipitate was separated by filtration and recrystallized from hot ethanol to provide the purified compound $(1.03 \mathrm{~g})$ in excellent yield. Single crystals, adequate for XRD measurements were obtained from slow evaporation of an ethanolic solution. The orange crystalline solid was identified as the keto-enamine tautomer: (5Z)-5(6-oxo-cyclohexa-2,4-dien-1-ylidene)-7-trifluoromethyl-2,3,4,5-tetrahydro- $1 \mathrm{H}-1,4-$ diazepine, $\mathbf{O}=$ DZP. Yield $\sim 1.03 \mathrm{~g}(98 \%)$; mp 206$209^{\circ} \mathrm{C}$.

4.3. X-ray Diffraction Data and Structure Refinement. The measurements were performed on an Oxford Xcalibur Gemini, Eos CCD diffractometer with graphite-monochromated $\operatorname{MoK} \alpha(\lambda=$ $0.71073 \AA$ ) radiation. X-ray diffraction intensities were collected ( $\omega$ scans with $\vartheta$ and $\kappa$-offsets), integrated, and scaled with the CrysAlisPro $^{40}$ suite of programs. The unit cell parameters were obtained by least-squares refinement (based on the angular setting for all collected reflections with intensities larger than seven times the standard deviation of measurement errors) using CrysAlisPro. Data were corrected empirically for absorption employing the multiscan method implemented in CrysAlisPro. The structure was solved by intrinsic phasing with SHELXT ${ }^{41}$ and the molecular model was refined by full-matrix least-squares procedure with SHELXL. ${ }^{42}$ The $-\mathrm{CF}_{3}$ group showed severe rotational disorder around the $\mathrm{C}-\mathrm{CF}_{3}$ bond, which could be modeled in terms of three split angular conformations with approximate equal occupancies. The three $\mathrm{C}-$ $\mathrm{CF}_{3}$ replicas were refined (with anisotropic displacement parameters) by restraining all of the $\mathrm{C}-\mathrm{F}$ bond lengths and $\mathrm{F} \cdots \mathrm{F}$ distances to be respectively equal to one another while restraining the occupancies such as to add up to one. At this stage, a difference Fourier map phased on the heavier atoms showed all of the $\mathrm{H}$ atoms. These were refined at their found positions with isotropic displacement parameters.

Crystal data and structure refinement results are summarized in Table S1. Crystallographic structural data have been deposited at the Cambridge Crystallographic Data Centre (CCDC). Enquiries for data can be direct to Cambridge Crystallographic Data Centre, 12 Union Road, Cambridge, UK, CB2 1EZ or (e-mail) deposit@ccdc.cam.ac.uk or $(\mathrm{fax})+44(0) 1223$ 336033. Any request to the Cambridge Crystallographic Data Centre for this material should quote the full literature citation and the reference number CCDC $1848050(\mathrm{O}=$ DZP).

4.4. Hirshfeld Surface Calculations. The Hirshfeld surface analysis is a well-known method to investigate in detail the characteristics of the crystal packing, such as polymorphism and other aspects of supramolecular assembly. Different functions describe specific properties of the Hirshfeld surface $\left(d_{\text {norm }}\right.$, shape index, or curvedness) allowing for intuitive recognition and visual analysis of interactions between molecules. All distances to the Hirshfeld surface $\left(d_{i}\right.$ and $\left.d_{e}\right)$ can be summarized in the form of two-dimensional diagrams (2D fingerprint plots), whose shapes are typical for certain close contacts environment. ${ }^{4-46} 2 \mathrm{D}$ fingerprint plots were used for decoding and quantifying the intermolecular interactions in the crystal lattice. Hirshfeld surfaces and their associated 2D fingerprint plots $^{43-46}$ were performed using the CrystalExplorer17 program. ${ }^{47}$ The $\mathbf{O}=\mathbf{D Z P}$ structural parameters were taken from the CIF file. The $3 \mathrm{D} d_{\text {norm }}$ (normalized contact distance) surfaces were mapped over a fixed color scale of -0.135 au (red) to 0.460 au (blue). The $2 \mathrm{D}$ fingerprint plots were displayed by using the translated $0.6-2.6 \AA$ range and including reciprocal contacts.

4.5. Computational Procedures. Quantum chemical calculations were performed using the Gaussian 03 program. ${ }^{48}$ The X-ray structure coordinates were used as starting parameters for geometry optimization at the B3LYP/6-311++G(d,p) level of theory. Vibrational frequencies were calculated to confirm the proper convergence to energy minima on the potential energy surface. The potential energy distribution was calculated with the VEDA4 program. ${ }^{49,50}$ For the electronic spectra, time-dependent density functional theory (TD$\mathrm{DFT})$ method $^{51}$ at B3LYP/6-311++G(d,p) approximation was used to compute energies and intensity of 20 lowest energy singlet to singlet electronic excitations in solution (ethanol and toluene) using PCM. ${ }^{52}$ NBO analysis, ${ }^{33}$ as implemented in the Gaussian 03 package, was performed at the B3LYP/6-311++G(d,p) level for the monomeric and for dimeric structures of the $\mathbf{O}=\mathbf{D Z P}$ molecule, in order to obtain second-order donor $\rightarrow$ acceptor interaction energies. The AIM2000 program ${ }^{53}$ was applied for the topological analysis of selected dimers identified from the crystal structure of $\mathbf{O}=\mathbf{D Z P}$. To evaluate the nature of different intra- and intermolecular interactions, some topological parameters such as electron density $(\rho)$, the Laplacian electron density $\left(\nabla^{2} \rho\right)$, local potential energy density $(V)$, and kinetic energy density $(G)$ at the bond critical points (BCPs) were calculated adopting the geometry of the crystal structure with normalized hydrogen positions at B3LYP/6-311++G(d,p) approximation. The energies of the intra- and intermolecular interactions were estimated using the formula proposed by Espinosa and coworkers. ${ }^{54}$ The molecular electrostatic potential (MEP) of the ketoenamine tautomeric form has also been calculated at the same level of theory.

\section{ASSOCIATED CONTENT}

\section{S Supporting Information}

The Supporting Information is available free of charge on the ACS Publications website at DOI: 10.1021/acs.joc.9b01533.

IR and Raman spectra, ${ }^{1} \mathrm{H}$ and ${ }^{13} \mathrm{C}$ NMR chemical shifts, theoretical calculation data, X-ray data collection, and crystallographic refinement statistics (PDF)

Crystal data for $\mathbf{O}=\mathbf{D Z P}(\mathrm{CIF})$

\section{AUTHOR INFORMATION}

\section{Corresponding Authors}

*E-mail: dmgil@fbqf.unt.edu.ar.

*E-mail: sonia@quimica.unlp.edu.ar.

ORCID

Sonia E. Ulic: 0000-0002-9179-9609

\section{Notes}

The authors declare no competing financial interest.

\section{ACKNOWLEDGMENTS}

This work was supported by ANPCyT (PICT 2016-0226), SACyT-UNT (Project D639/2), CONICET (Grant Nos. PIP 11220130100651CO, PIP 0359), and UNLP (Grant Nos. 11/ X709 and 11X/830) of Argentina. D.M.G., G.A.E., O.E.P., and S.E.U. are research fellows and M.R. is a doctoral fellow of CONICET. J.L.J. is a research fellow of Comisión de Investigaciones Cientificas de la Prov. de Buenos Aires (CIC). We thank Prof. Peter Langer, Chemistry Institute, Rostock University, for use of the spectroscopic facilities. 


\section{REFERENCES}

(1) Sternbach, L.; Randall, L.; Banziger, R.; Lehr, H., Structureactivity relationships in the 1,4-benzodiazepine series. In Drugs affecting the central nervous system; Burger, E. A., Ed.; Marcel Dekker, Inc.: New York, 1968; Vol. 2, pp 237-264.

(2) Meanwell, N. A.; Walker, M. A., 1,4-Diazepines. In Comprehensive Heterocyclic Chemistry III; Katritzky, A. R., Ramsden, C. A., Scriven, E. F. V., Taylor, R. J. K., Eds.; Elsevier, Ltd.: Oxford, 2008; Vol. 13, pp 183-235.

(3) Ryan, J. H.; Hyland, C.; Just, J.; Meyer, A. G.; Smith, J. A.; Williams, C. C., Chapter 6 - Seven-Membered Rings. In Progress in Heterocyclic Chemistry; Gribble, G. W., Joule, J. A., Eds.; Elsevier: Netherlands, 2013; Vol. 25, pp 455-495.

(4) Archer, G. A.; Sternbach, L. H. Chemistry of benzodiazepines. Chem. Rev. 1968, 68 (6), 747-784.

(5) Goodman, L. S.; Brunton, L. L.; Chabner, B.; Knollmann, B. r. C. Goodman \& Gilman's the pharmacological basis of therapeutics, 12th ed.; McGraw-Hill: New York, 2011.

(6) Kumar, R.; Joshi, Y. C. Synthesis, antimicrobial and antifungal activities of novel $1 \mathrm{H}-1,4$-diazepines containing pyrazolopyrimidinone moiety. J. Chem. Sci. 2009, 121 (4), 497-502.

(7) Kenchappa, R.; Bodke, Y. D.; Telkar, S.; Nagaraja, O. Synthesis and antimicrobial activity of fused isatin and diazepine derivatives derived from 2-acetyl benzofuran. Russ. J. Gen. Chem. 2017, 87 (9), 2027-2038.

(8) Biradar, J. S.; Somappa, S. B. Synthesis of novel Indolyl benzo[b][1,4]diazepins as potent antimicrobial and antioxidant agents. Arabian J. Chem. 2016, 9, S1063-S1068.

(9) Henderson, E. A.; Alber, D. G.; Baxter, R. C.; Bithell, S. K.; Budworth, J.; Carter, M. C.; Chubb, A.; Cockerill, G. S.; Dowdell, V. C. L.; Fraser, I. J.; Harris, R. A.; Keegan, S. J.; Kelsey, R. D.; Lumley, J. A.; Stables, J. N.; Weerasekera, N.; Wilson, L. J.; Powell, K. L. 1,4Benzodiazepines as Inhibitors of Respiratory Syncytial Virus. The Identification of a Clinical Candidate. J. Med. Chem. 2007, 50 (7), $1685-1692$.

(10) Ghogare, J. G.; Bhandari, S. V.; Bothara, K. G.; Madgulkar, A. R.; Parashar, G. A.; Sonawane, B. G.; Inamdar, P. R. Design, synthesis and pharmacological screening of potential anticonvulsant agents using hybrid approach. Eur. J. Med. Chem. 2010, 45 (3), 857-863.

(11) Gill, R. K.; Kaushik, S. O.; Chugh, J.; Bansal, S.; Shah, A.; Bariwal, J. Recent development in $[1,4]$ benzodiazepines as potent anticancer agents: a review. Mini-Rev. Med. Chem. 2014, 14 (3), 229256.

(12) Karp, G. M.; Manfredi, M. C.; Guaciaro, M. A.; Ortlip, C. L.; Marc, P.; Szamosi, I. T. Synthesis and Herbicidal Activity of 1H-1,4Benzodiazepine-2,5-diones. J. Agric. Food Chem. 1997, 45 (2), 493500.

(13) Kukla, M. J.; Breslin, H. J.; Diamond, C. J.; Grous, P. P.; Ho, C. Y.; Miranda, M.; Rodgers, J. D.; Sherrill, R. G.; De Clercq, E.; Pauwels, R.; Andries, K.; Moens, L. J.; Janssen, M. A. C.; Janssen, P. A. J. Synthesis and anti-HIV-1 activity of 4,5,6,7-tetrahydro-5methylimidazo[4,5,1-jk][1,4]benzodiazepin-2(1H)-one (TIBO) derivatives. 2. J. Med. Chem. 1991, 34 (11), 3187-3197.

(14) Dunitz, J. D.; Gavezzotti, A. Supramolecular Synthons: Validation and Ranking of Intermolecular Interaction Energies. Cryst. Growth Des. 2012, 12 (12), 5873-5877.

(15) Schmidt, M. U.; Brüning, J.; Glinnemann, J.; Hützler, M. W.; Mörschel, P.; Ivashevskaya, S. N.; van de Streek, J.; Braga, D.; Maini, L.; Chierotti, M. R.; Gobetto, R. The Thermodynamically Stable Form of Solid Barbituric Acid: The Enol Tautomer. Angew. Chem., Int. Ed. 2011, 50 (34), 7924-7926.

(16) Marshall, M. G.; Lopez-Diaz, V.; Hudson, B. S. Single-Crystal X-ray Diffraction Structure of the Stable Enol Tautomer Polymorph of Barbituric Acid at 224 and $95 \mathrm{~K}$. Angew. Chem., Int. Ed. 2016, 55 (4), 1309-1312.

(17) Loew, G. H.; Nienow, J. R.; Poulsen, M. Theoretical structureactivity studies of benzodiazepine analogues. Requirements for receptor affinity and activity. Molecular pharmacology 1984, 26 (1), 19-34.
(18) Chen, Z.; Guieu, S.; White, N. G.; Lelj, F.; MacLachlan, M. J. The Rich Tautomeric Behavior of Campestarenes. Chem. - Eur. J. 2016, 22 (49), 17657-17672.

(19) Antonov, L.; Fabian, W. M. F.; Nedeltcheva, D.; Kamounah, F. S. Tautomerism of 2-hydroxynaphthaldehyde Schiff bases. Journal of the Chemical Society, Perkin Transactions 2 2000, No. 6, 1173-1179.

(20) Sosnovskikh, V. Y.; Vorontsov, I. I.; Kutsenko, V. A. 2Polyfluoroalkylchromones. 9. Synthesis and structures of 5-(2hydroxyaryl)-7-polyfluoroalkyl-1,4,8-triazabicyclo[5.3.0] dec-4-enes. Russ. Chem. Bull. 2001, 50, 1430-1438.

(21) Ozek, A.; Albayrak, C.; Odabasoglu, M.; Buyukgungor, O. Three (E)-2-[(bromophenyl)iminomethyl]-4-methoxyphenols. Acta Crystallogr., Sect. C: Cryst. Struct. Commun. 2007, 63 (3), o177-o180.

(22) Kosar, B.; Albayrak, C.; Odabasoglu, M.; Buyukgungor, O. 2Hydroxy-6-[(2-hydroxyphenylamino)methylene]cyclohexa-2,4-dienone. Acta Crystallogr., Sect. E: Struct. Rep. Online 2005, 61 (4), o1097-o1099.

(23) Koşar, B.; Albayrak, Ç; Odabaşoğlu, M.; Büyükgüngör, O. Theoretical and experimental studies on electronic structure, cocrystallization, and intramolecular proton transfer of two tautomers: (E)-2-\{[2-(hydroxymethyl)phenylimino]methyl $\}-5$-methoxyphenol and (Z)-6-\{[2-(hydroxymethyl)phenylamino] methylene $\}-3-m e-$ thoxy-cyclohexa-2, 4-dienone. Int. J. Quantum Chem. 2010, 111 (14), 3654-3663.

(24) Pis Diez, R.; Echeverria, G. A.; Piro, O. E.; Jios, J. L.; Parajon Costa, B. S. Structural, Spectroscopic and Theoretical Study of an ovanillin Schiff base derivative involved in enol-imine and keto-amine tautomerism. New J. Chem. 2016, 40, 2730-2740.

(25) Gilli, G.; Bellucci, F.; Ferretti, V.; Bertolasi, V. Evidence for resonance-assisted hydrogen bonding from crystal-structure correlations on the enol form of the.beta.-diketone fragment. J. Am. Chem. Soc. 1989, 111 (3), 1023-1028.

(26) Zubatyuk, R. I.; Volovenko, Y. M.; Shishkin, O. V.; Gorb, L.; Leszczynski, J. Aromaticity-Controlled Tautomerism and ResonanceAssisted Hydrogen Bonding in Heterocyclic Enaminone-Iminoenol Systems. J. Org. Chem. 2007, 72 (3), 725-735.

(27) Seth, S. K. Tuning the formation of MOFs by pH influence: Xray structural variations and Hirshfeld surface analyses of 2-amino-5nitropyridine with cadmium chloride. CrystEngComm 2013, 15 (9), $1772-1781$

(28) Seth, S. K.; Sarkar, D.; Jana, A. D.; Kar, T. On the Possibility of Tuning Molecular Edges To Direct Supramolecular Self-Assembly in Coumarin Derivatives through Cooperative Weak Forces: Crystallographic and Hirshfeld Surface Analyses. Cryst. Growth Des. 2011, 11 (11), 4837-4849.

(29) Koch, U.; Popelier, P. L. A. Characterization of C-H-O Hydrogen Bonds on the Basis of the Charge Density. J. Phys. Chem. 1995, 99 (24), 9747-9754.

(30) Mo, Y. Can QTAIM Topological Parameters Be a Measure of Hydrogen Bonding Strength? J. Phys. Chem. A 2012, 116 (21), 52405246.

(31) Majerz, I. The influence of potassium cation on a strong $\mathrm{OHO}$ hydrogen bond. Org. Biomol. Chem. 2011, 9 (5), 1466-1473.

(32) Rozas, I.; Alkorta, I.; Elguero, J. Behavior of Ylides Containing $\mathrm{N}, \mathrm{O}$, and C Atoms as Hydrogen Bond Acceptors. J. Am. Chem. Soc. 2000, 122 (45), 11154-11161.

(33) Reed, A. E.; Curtiss, L. A.; Weinhold, F. Intermolecular Interactions from a Natural Bond Orbital, Donor-Acceptor Viewpoint. Chem. Rev. 1988, 88 (6), 899-926.

(34) Lopes, R. P.; Marques, M. P. M.; Valero, R.; Tomkinson, J.; de Carvalho, L. A. E. B. Guanine: A Combined Study Using Vibrational Spectroscopy and Theoretical Methods. Spectroscopy: Int. J. 2012, 27 (5-6), 20.

(35) Dziembowska, T.; Szafran, M.; Katrusiak, A.; Rozwadowski, Z. Crystal structure of and solvent effect on tautomeric equilibrium in Schiff base derived from 2-hydroxy-1-naphthaldehyde and methylamine studied by X-ray diffraction, DFT, NMR and IR methods. J. Mol. Struct. 2009, 929 (1), 32-42. 
(36) Ahumada, G.; Carrillo, D.; Manzur, C.; Fuentealba, M.; Roisnel, T.; Hamon, J.-R. A facile access to new diazepines derivatives: Spectral characterization and crystal structures of 7(thiophene-2-yl)-5-(trifluoromethyl)-2,3-dihydro-1H-1,4-diazepine and 2-thiophene-4-trifluoromethyl-1,5-benzodiazepine. J. Mol. Struct. 2016, 1125, 781-787.

(37) Ünver, H.; Polat, K.; Uçar, M.; Zengin, D. M. Synthesis and keto-enol tautomerism in N-(2-hydroxy-1-naphthylidene)anils. Spectrosc. Lett. 2003, 36, 287-301.

(38) Claramunt, R. M.; López, C.; Santa María, M. D.; Sanz, D.; Elguero, J. The use of NMR spectroscopy to study tautomerism. Prog. Nucl. Magn. Reson. Spectrosc. 2006, 49 (3-4), 169-206.

(39) Mehr, S. H. M.; Fukuyama, K.; Bishop, S.; Lelj, F.; MacLachlan, M. J. Deuteration of Aromatic Rings under Very Mild Conditions through Keto-Enamine Tautomeric Amplification. J. Org. Chem. 2015, 80 (10), 5144-5150.

(40) CrysAlisPro 1.171.33.48; Oxford Diffraction Ltd., 2009.

(41) Sheldrick, G. SHELXT - Integrated space-group and crystalstructure determination. Acta Crystallogr., Sect. A: Found. Adv. 2015, $71(1), 3-8$.

(42) Sheldrick, G. A short history of SHELX. Acta Crystallogr., Sect. A: Found. Crystallogr. 2008, 64 (1), 112-122.

(43) McKinnon, J. J.; Spackman, M. A.; Mitchell, A. S. Novel tools for visualizing and exploring intermolecular interactions in molecular crystals. Acta Crystallogr., Sect. B: Struct. Sci. 2004, 60 (6), 627-668.

(44) McKinnon, J. J.; Jayatilaka, D.; Spackman, M. A. Towards quantitative analysis of intermolecular interactions with Hirshfeld surfaces. Chem. Commun. 2007, No. 37, 3814-3816.

(45) Spackman, M. A.; Jayatilaka, D. Hirshfeld surface analysis. CrystEngComm 2009, 11 (1), 19-32.

(46) Spackman, M. A. Molecular electric moments from x-ray diffraction data. Chem. Rev. 1992, 92 (8), 1769-1797.

(47) Turner, M. J.; McKinnon, J. J.; Wolff, S. K.; Grimwood, D. J.; Spackman, P. R.; Jayatilaka, D.; Spackman, M. A. CrystalExplorer17, 2017.

(48) Frisch, M. J.; Trucks, G. W.; Schlegel, H. B.; Scuseria, G. E.; Robb, M. A.; Cheeseman, J. R.; Montgomery, J. A., Jr.; Vreven, T.; Kudin, K. N.; Burant, J. C.; Millam, J. M.; Iyengar, S. S.; Tomasi, J.; Barone, V.; Mennucci, B.; Cossi, M.; Scalmani, G.; Rega, N.; Petersson, G. A.; Nakatsuji, H.; Hada, M.; Ehara, M.; Toyota, K.; Fukuda, R.; Hasegawa, J.; Ishida, M.; Nakajima, T.; Honda, Y.; Kitao, O.; Nakai, H.; Klene, M.; Li, X.; Knox, J. E.; Hratchian, H. P.; Cross, J. B.; Adamo, C.; Jaramillo, J.; Gomperts, R.; Stratmann, R. E.; Yazyev, O.; Austin, A. J.; Cammi, R.; Pomelli, C.; Ochterski, J. W.; Ayala, P. Y.; Morokuma, K.; Voth, G. A.; Salvador, P.; Dannenberg, J. J.; Zakrzewski, V. G.; Dapprich, S.; Daniels, A. D.; Strain, M. C.; Farkas, O.; Malick, D. K.; Rabuck, A. D.; Raghavachari, K.; Foresman, J. B.; Ortiz, J. V.; Cui, Q.; Baboul, A. G.; Clifford, S.; Cioslowski, J.; Stefanov, B. B.; Liu, G.; Liashenko, A.; Piskorz, P.; Komaromi, I.; Martin, R. L.; Fox, D. J.; Keith, T.; Al-Laham, M. A.; Peng, C. Y.; Nanayakkara, A.; Challacombe, M.; Gill, P. M. W.; Johnson, B.; Chen, W.; Wong, M. W.; Gonzalez, C.; Pople, J. A. Gaussian 03, Revision B.04; Gaussian, Inc.: Pittsburgh, PA, 2003.

(49) Jamróz, M. H. Vibrational energy distribution analysis (VEDA): scopes and limitations. Spectrochim. Acta, Part A 2013, 114, 220-30.

(50) Jamróz, M. H. Vibrational energy distribution analysis: VEDA 4 program, Warsaw, 2004.

(51) Stratmann, E. R.; Scuseria, G. E.; Frisch, M. J. An effecient implementation of time-dependent density-functional theory for the calculation of excitation energies of large molecules. J. Chem. Phys. 1998, 109 (19), 8218-8224.

(52) Cossi, M.; Rega, N.; Scalmani, G.; Barone, V. Energies, structures, and electronic properties of molecules in solution with the C-PCM solvation model. J. Comput. Chem. 2003, 24 (6), 669-81.

(53) Bader, R. F. W. Atoms in Molecules: A Quantum Theory; Oxford University Press: Oxford, 1990.

(54) Espinosa, E.; Molins, E.; Lecomte, C. Hydrogen bond strengths revealed by topological analyses of experimentally observed electron densities. Chem. Phys. Lett. 1998, 285 (3), 170-173. 